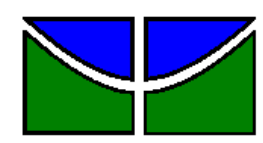

Universidade de Brasília

Faculdade de Economia, Administração, Contabilidade e Ciências da Informação e Documentação

INGRED CASTRO DE ALMEIDA

\author{
SATISFAÇÃO E COMPROMETIMENTO DAS EQUIPES DE \\ TRABALHO DE UMA PENITENCIÁRIA DO DISTRITO FEDERAL
}

Brasília - DF

Dezembro / 2009 
Universidade de Brasília

Faculdade de Economia, Administração, Contabilidade e Ciências da Informação e Documentação

\section{INGRED CASTRO DE ALMEIDA}

\section{SATISFAÇÃO E COMPROMETIMENTO DAS EQUIPES DE TRABALHO DE UMA PENITENCIÁRIA DO DISTRITO FEDERAL}

Trabalho de conclusão de curso apresentado ao Departamento de Administração como requisito parcial à obtenção do título de Bacharel em Administração.

Professora Orientadora: Dra. Maria de Fátima Bruno-Faria

$$
\text { Brasília - DF }
$$


Almeida, Ingred Castro de.

Satisfação e comprometimento das equipes de trabalho de uma penitenciária do distrito federal / Ingred Castro de Almeida. - Brasília, 2009.

$51 \mathrm{f}$. : il.

Monografia (bacharelado) - Universidade de Brasília, Departamento de Administração, 2009.

orientador: Prof ${ }^{a}$. Dra. Maria de Fátima Bruno-Faria, Departamento de Administração.

1. Equipe de trabalho. 2. Satisfação com a equipe. 3.

Comprometimento com a equipe. 4. Penitenciária do Distrito Federal. I. Título. 
Universidade de Brasília

Faculdade de Economia, Administração, Contabilidade e Ciências da Informação e Documentação

\title{
SATISFAÇÃO E COMPROMETIMENTO DAS EQUIPES DE TRABALHO DE UMA PENITENCIÁRIA DO DISTRITO FEDERAL
}

A Comissão Examinadora, abaixo identificada, aprova o Trabalho de Conclusão do Curso de Administração da Universidade de Brasília da aluna

\section{INGRED CASTRO DE ALMEIDA}

\author{
Dra. Maria de Fátima Bruno-Faria \\ Professora-Orientadora \\ Especialista, Marcelo Magno Rocha \\ Nascimento \\ Professor-Examinador \\ Mestre, Domingos Savio Spezia \\ Professor-Examinador
}


À minha amada mãe, Lucimar Borges, a quem serei eternamente grata por ter me ensinado que é preciso ter força, coragem, determinação e persistência para alcançar meus objetivos. É também com saudade infinda que dedico este trabalho e todas as minhas vitorias àquela que se tornou meu exemplo de vida e o motivo pelo qual luto para realizar meus sonhos. 
Agradeço, primeiramente, à Deus por te me dado a vida, amparo e ânimo nos momentos difíceis. E por ter me concedido sabedoria e coragem para estudar e concretizar esta pesquisa.

A professora Maria de Fátima Bruno-Faria, minha orientadora, pela confiança depositada nesse trabalho, por compartilhar seus valiosos conhecimentos, pelas orientações, pelos contínuos incentivos, enfim, por todo o amparo necessário para a realização deste estudo.

Ao Delegado, Dr. Celso Wagner, pela confiança depositada no meu trabalho.

Às equipes participantes da pesquisa, servidores da penitenciária, pelas valiosas informações e pela participação aberta e voluntária ao trabalho.

Ao meu namorado, Igor, pelo apoio e incentivo para realizar este trabalho.

Aos meus familiares que confiaram na minha capacidade profissional. Em especial ao meu tio Leônidas, meu "pai de coração", pela compreensão, paciência, cooperação, apoio e carinho durante toda a minha vida. E à minha tia, Osmarina Borges, por sempre ter me incentivado a estudar. Amo muito vocês!!!

Por último, mas em primeiro lugar no coração, ao meu filho querido, Henrique, agradeço a compreensão pelos momentos de ausência, pelo carinho, por sempre me ouvir e acreditar na minha competência. 


\section{RESUMO}

O presente estudo tem como objetivo principal analisar os níveis de satisfação e comprometimento dos servidores de uma penitenciária do Distrito Federal em relação as suas equipes de trabalho. Para atingir tal objetivo, primeiramente apresentaram-se as origens do novo modelo de gestão que adota as equipes de trabalho como unidades de desempenho. Em seguida, foram apresentadas as definições sobre trabalho em equipes, onde se adotou a de Machado (1998) como princípio orientador deste trabalho e foram abordadas algumas definições sobre Satisfação e Comprometimento com a equipe e a relação com a efetividade da equipe. A presente pesquisa tem natureza quantitativa, descritiva e correlacional. Ela contou com a participação de 176 servidores, componentes de 17 equipes do expediente e das quatro do plantão da penitenciária. Os dados foram obtidos através de questionários aplicados com os servidores da organização (survey) onde o instrumento utilizado é composto pelas escalas que medem a satisfação e comprometimento com as equipes de trabalho, questões sócio-demográficas e uma questão aberta no final para observações por parte dos respondentes da pesquisa. Foram calculadas médias e desvio padrão dos fatores que compõem as duas escalas, assim como correlação de Pearson entre os fatores e as variáveis sóciodemograficas. Os resultados encontrados revelaram satisfação e comprometimento com a equipe por parte da maioria dos participantes. Já as correlações feitas entre os fatores estudados e as variáveis sócio-demográficas apontaram relações significativas entre estes fatores e as variáveis: sexo e regime de trabalho. Ou seja, as mulheres são menos satisfeitas e comprometidas com a equipe do que os homens; e os servidores do plantão também são mais satisfeitos e comprometidos com a equipe do que os do expediente. As observações feitas na questão aberta dos questionários indicam que fatores externos à equipe (como salário e reconhecimento do serviço) também influenciam nos níveis de Satisfação e Comprometimento com a equipe.

PALAVRAS-CHAVES: Equipe de trabalho. Satisfação com a equipe. Comprometimento com a equipe. Penitenciária do Distrito Federal. 


\section{LISTA DE TABELAS}

Tabela 1: Distribuição dos servidores do expediente por seção.

Tabela 2: Distribuição dos servidores participantes, agrupados em cargo e idade...31

Tabela 3: Distribuição dos servidores em relação ao tempo de serviço e o grau de escolaridade.

Tabela 4: Média e desvio padrão das Escalas satisfação e comprometimento com a equipe de trabalho.

Tabela 5: Média e desvio padrão dos itens que compõem o fator Satisfação com a equipe de trabalho.

Tabela 6: Média e desvio padrão dos itens que compõem o fator Comprometimento com a equipe de trabalho. .34 


\section{SUMÁRIO}

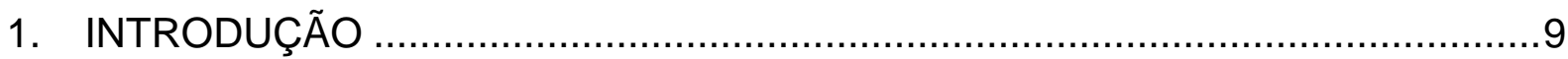

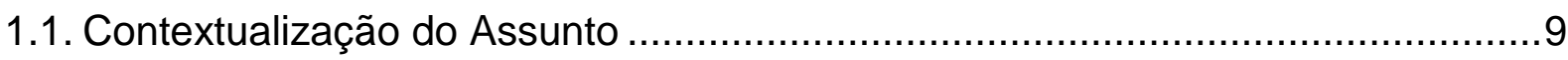

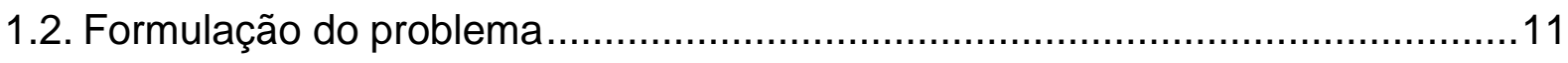

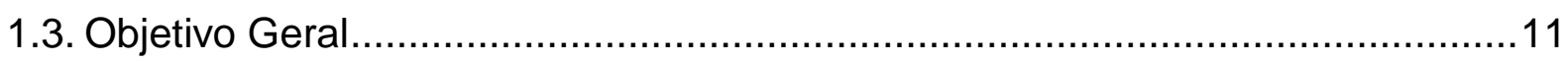

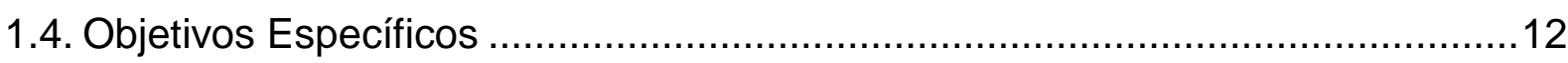

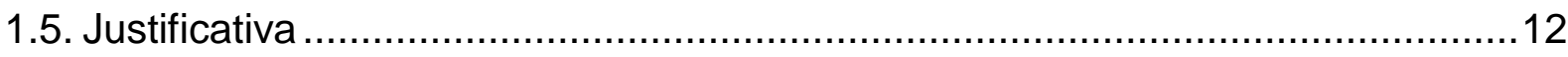

1.6. Métodos e Técnicas de Pesquisa ................................................................

1.7. Estrutura e Organização da Monografia .......................................................14

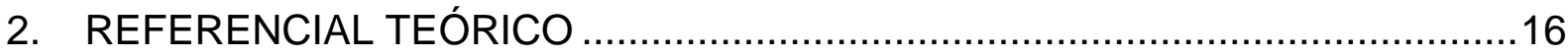

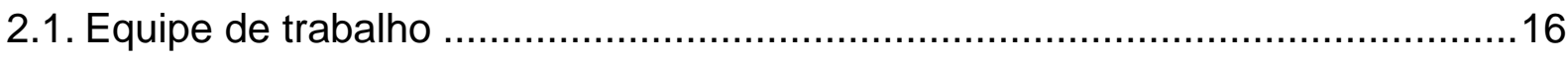

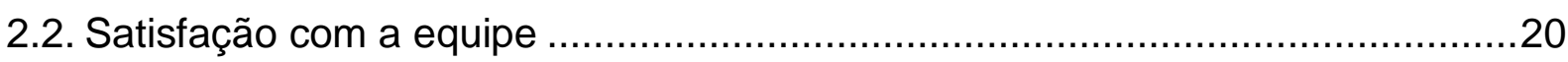

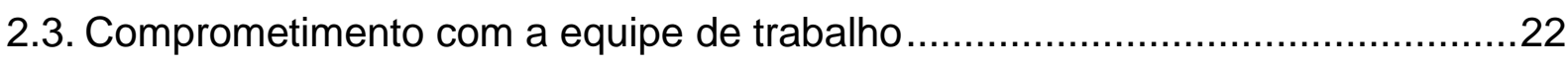

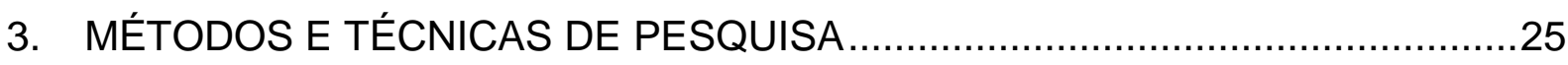

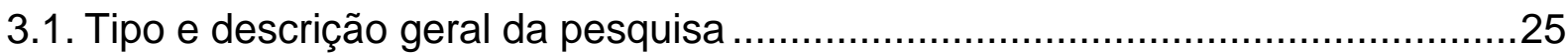

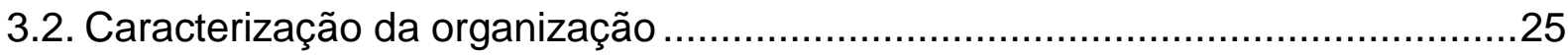

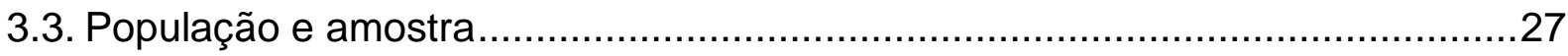

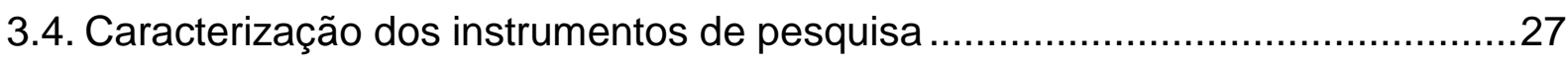

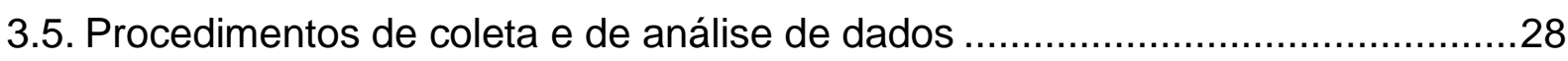

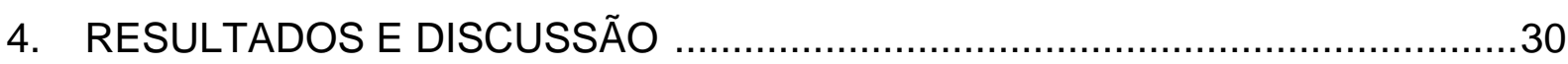

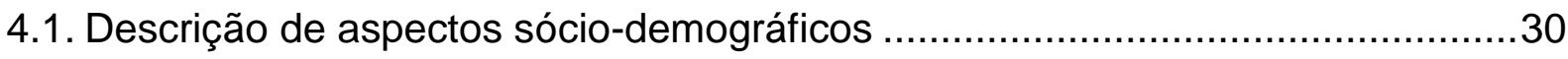

4.2. Níveis da Satisfação e Comprometimentos das equipes .................................32

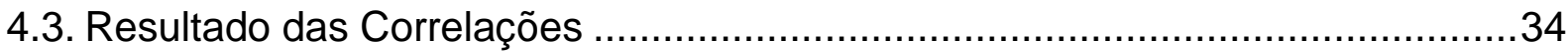

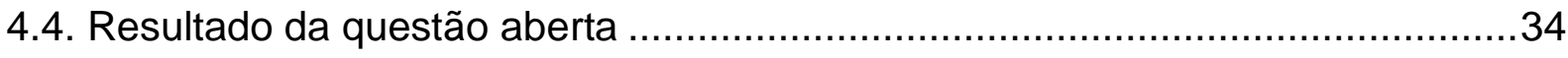

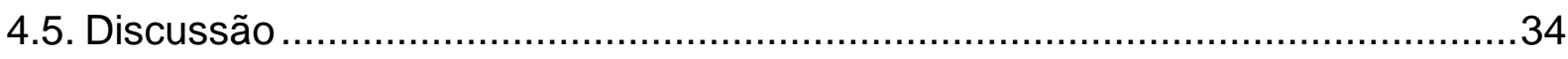

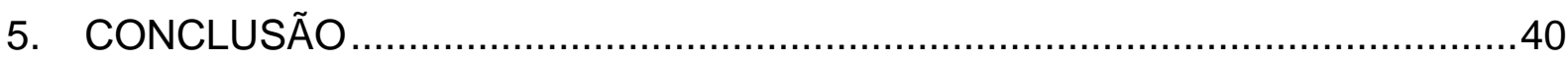

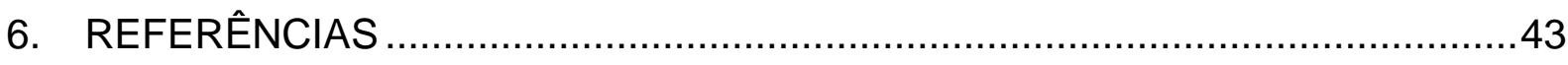

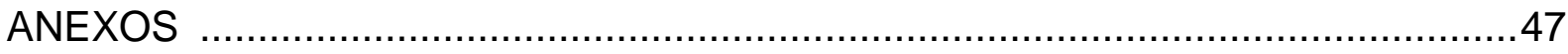

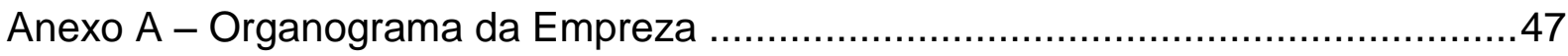

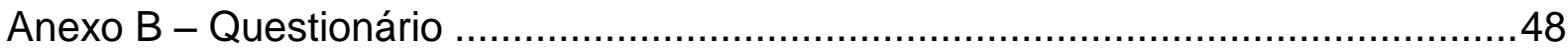




\section{INTRODUÇÃO}

Objetivou-se com o presente estudo identificar e analisar os fatores que afetam significativamente os níveis de satisfação e comprometimento dos membros de uma equipe de trabalho. Maiores informações sobre a contextualização do assunto, problema, objetivos, justificativa, métodos e estrutura da Monografia serão apresentados a seguir.

\subsection{Contextualização do Assunto}

Conforme Machado (1998) a abertura dos países ao comercio internacional fez crescer a competitividade das organizações em diversas partes do mundo. Como conseqüência veio o desenvolvimento científico e tecnológico.

Passou-se a vivenciar a "Era do Conhecimento" que enfatiza o estudo da Gestão de pessoas e as consideram com o capital intelectual das empresas. Segundo Nascimento et al. (2003), as organizações atuais, na incessante busca pela qualidade, produtividade e competitividade, passaram a incorporar novos padrões de relação de trabalho onde procuram uma maior disseminação dos trabalhadores na tomada de decisões das empresas.

O interesse pelo estudo da influência que grupos exercem sobre 0 comportamento e/ou desempenho dos indivíduos não é uma temática nova. PuentePalacios (2002, p. 4) afirma que "remonta às primeiras décadas do século $X X$, quando Elton Mayo pôde verificar que os trabalhadores atribuem grande valor às relações sociais que mantêm no seu local de trabalho". Porém, a autora constatou que o primeiro artigo voltado especificamente para o estudo do desempenho de equipes de trabalho em organizações foi escrito em 1996 por Guzzo e Dickson. Para Ishara (2007 p. 3) "o desempenho de uma organização está sujeito ao conjunto de relações estabelecidas entre as pessoas que ali trabalham", ou seja, as relações interpessoais entre os membros podem ajudar ou prejudicar no desempenho do trabalho.

As novas formas de gestão empresarial passaram por processos de mudança estruturais ao longo dos anos. Por isso as empresas começaram a adotar a formação de equipes de trabalho como unidades de desempenho (DUHÁ, 2007; 
SACOMANO NETO; ESCRIVÃO FILHO, 2000; PUENTE-PALACIOS, 2002); a desenvolver dinâmicas de grupo (CARTWRIGHT, 1966); a desenvolver uma cultura organizacional "Sedimentada" para transformar grupos de colaboradores em equipes (BERSOU; BERSOU, 1997) e a estudar como desenvolver equipes na melhoria de resultados organizacionais (PIERUCCINI, 2002). Nos últimos anos as empresas também passaram a estudar os elementos que limitam e promovem significativamente a efetividade das equipes de trabalho e vendo estes elementos como fatores determinantes do trabalho de um grupo eficaz (DUHÁ, 2007).

Sousa (2006, p.30) após estudar as variáveis que impactam de maneira efetiva o desempenho das equipes de trabalho constatou que a satisfação e o comprometimento são indicadores afetivos presentes na maioria dos estudos da área. A autora defende que "um dos principais desafios de uma organização atualmente é conseguir desenvolver uma força de trabalho talentosa, comprometida e disposta a realizar um trabalho árduo em prol da organização".

Puente-Palacios, Seidl e Silva $(2008$, p.83) defendem que "a satisfação é o vínculo afetivo positivo estabelecido com a unidade de desempenho, como resultado de experiências favoráveis vivenciadas ao longo do trabalho". Assim, a convivência positiva entre os membros da equipe de trabalho têm elevada probabilidade de gerar vínculos afetivos entre eles, ou seja, membros satisfeitos e melhores resultados para a organização.

Com relação ao comprometimento, o estudo de Guimarães e Martins (2008, p.71), que tinha como um dos seus objetivos estudar o comprometimento com a equipe de trabalho, afirma que "pode-se considerar que os tipos de comprometimentos com bases afetivas se destacam como aspectos fundamentais na compreensão do comportamento e de atitudes dos trabalhadores".O estudo concluiu que o comprometimento organizacional afetivo tem grande importância nos resultados de desempenho do empregado e da organização, como, por exemplo, menor rotatividade, menor absenteísmo e maior esforço do empregado no trabalho.

As experiências do autor deste estudo, a partir da sua participação no papel de integrante de uma equipe de trabalho em uma penitenciária, permitem concluir acerca da riqueza de recursos disponíveis no interior de uma equipe neste tipo de organização. A convivência profissional cotidiana possibilitou observar, preciosas 
trocas e benefícios. A perspectiva de focalizar a atenção nas equipes do sistema prisional foi se constituindo em um potente fator motivador para esta pesquisa.

\subsection{Formulação do problema}

Machado (1998) concluiu que a ênfase nas equipes de trabalho é um fenômeno global e que além de ser considerada uma regra nas organizações no futuro, ela já faz parte da realidade diária das pessoas, e dada sua complexidade, merece estudos sistemáticos.

Embora a adoção de equipes de trabalho como unidades de desempenho tenha sido rapidamente difundida e implantada em muitas empresas brasileiras, Borba (2007, p.94) afirma que "esse ainda é um tema pouco explorado pelos pesquisadores da área de comportamento organizacional”. A autora conclui que há escassez de instrumentos psicometricamente válidos para mensurar o fenômeno desse tipo de agrupamentos sociais.

Souza (2006, p.130) em sua dissertação sobre "O papel do autoconceito profissional na efetividade das Equipes de Trabalho" conclui defendendo a continuação da adoção do comprometimento como um indicador de efetividade. Ela também afirma que "pesquisas que mensurem o comprometimento calculativo com a equipe devem ser realizadas, pois esse tipo de vínculo tem se mostrado relevante em pesquisas sobre o comprometimento organizacional".

Considerando o contexto apresentado, este pesquisa se propôs a responder a seguinte pergunta: qual o grau de satisfação e comprometimento com a equipe de trabalho dos servidores de duas áreas distintas de uma penitenciária do Distrito Federal?

\subsection{Objetivo Geral}

O objetivo central do presente estudo é analisar os níveis de satisfação e comprometimento dos servidores de uma penitenciária do Distrito Federal com suas equipes de trabalho. 


\subsection{Objetivos Específicos}

Tendo em vista o objetivo geral, os seguintes objetivos específicos norteiam a realização da pesquisa:

1. Descrever as características do ambiente de trabalho das equipes de uma penitenciária;

2. Correlacionar os índices gerais de satisfação e comprometimento das equipes com as variáveis sócio-demográficas: idade, sexo, regime de trabalho, grau de escolaridade e tempo de serviço;

3. Comparar o grau de satisfação e de comprometimento das equipes que trabalham em dois regimes distintos em uma penitenciária do Distrito Federal.

\subsection{Justificativa}

A adoção de equipes de trabalho como unidades de desempenho tem se tornado uma prática cada vez mais frequente nas organizações modernas. Conforme ressaltam Puente-Palacios e Borges-Andrade (2005, p.58) "este incremento pode ser considerado efeito dos processos de mudança, sofridos pelas organizações em resposta às pressões exercidas pelo meio ambiente, que cobra respostas efetivas às suas demandas".

Souza (2006, p.1), após estudar diferentes autores, enfatiza que "o crescente interesse pela compreensão das equipes no mundo do trabalho levou à construção de diversos modelos teóricos que buscam explicar o funcionamento destas unidades no âmbito das organizações". No entanto, Borba (2007) afirma que com o aumento da implementação do trabalho em equipes nas organizações e por serem escassas pesquisas sobre o assunto no Brasil é relevante se investir em estudos que abordem o desempenho de equipes de trabalho e suas variáveis relacionadas.

No intuito de estudar um tipo organizacional pouco estudado entre os pesquisadores da área de Recursos Humanos, este trabalho busca contribuir para a construção de conhecimento sobre equipes de trabalho no contexto de uma penitenciária brasiliense. Já que o sistema penitenciário brasileiro tem uma estrutura gigantesca, segundo o Departamento Penitenciário Nacional (DEPEN, 2007), ele é o 
maior na América Latina, composto por 1.134 estabelecimentos prisionais e onde, na maioria dos casos, estas unidades sofrem problemas sérios como: superlotação, número reduzido do pessoal, péssimas condições de trabalho, entre outras que geram tensões constantes, entre seus servidores e os presos que ali estão.

No Brasil, cada estado que compõe a federação é responsável pela organização e administração do seu sistema penitenciário. O governo federal tem competências restritas sobre essas instituições e em geral exerce um papel de distribuidor de recursos financeiros para os estados, sem dispor de instrumentos eficazes de controle sobre o desempenho técnico e administrativo do sistema penitenciário. Como conseqüência disso são constantes as rebeliões nestas organizações.

Para Salla (2006, p.276) "as rebeliões nada mais são que formas de protesto, de inconformismo, contra a imposição de situações adversas que envolvem, por exemplo, a superlotação, a alimentação ruim, os maus tratos, etc". Pesquisando em vários periódicos científicos da área de Administração, classificados pela CAPES como A e B entre (2000 - 2009), poucos trabalhos que tem como temática o Sistema Penitenciário foram encontrados. Contudo, assim como Salla estes poucos estudos brasileiros sobre o Sistema Penitenciário só apontam os diversos problemas enfrentados pelo sistema prisional e evidenciam a ineficiência do Estado em controlá-lo. A pesquisa dirigida aos indivíduos que trabalham no Sistema Penitenciário brasileiro tem despertado pouco ou quase nenhum interesse entre os estudiosos do assunto, isso é concluído pela quase inexistência de publicações a respeito. Só foi encontrado um estudo com a intenção de analisar os servidores penitenciários. Todavia, este foi desenvolvido por Fernandes et al. (2000) e teve como objetivo identificar possíveis associações entre condições de trabalho e saúde de agentes penitenciários da região de Salvador - Bahia.

Tendo como base tudo que foi dito acima, concluiu-se que é relevante o estudo dos elementos que limitam e promovem significativamente o efetivo desempenho das equipes de trabalho das organizações. Após revisar alguns teóricos que desenvolveram pesquisas sobre as variáveis presentes na avaliação dos indicadores da efetividade do desempenho das equipes (MACHADO, 1998; PUENTEPALACIOS, 2002; SOUZA, 2006; DUHÁ, 2007; PUENTE-PALACIOS, SEIDL ; SILVA, 2008), constatou-se que a satisfação e o comprometimento são variáveis 
presentes em todos os estudos, pois são uma resposta afetiva das relações interpessoais no trabalho e influenciam no desempenho da organização.

Do ponto de vista teórico, espera-se que este estudo contribua para o avanço das investigações sobre administração de pessoas dada a importância de se aprofundar o estudo dos indicadores afetivos envolvidos nas relações interpessoais que ocorrem entre os membros das equipes de trabalho dos diversos tipos de organizações.

A escolha de uma penitenciária como objeto de estudo está baseada no fato do interesse público nos resultados efetivos do trabalho desempenhado pelos servidores do sistema penitenciário brasileiro, pois este é um tema corrente na Mídia como fonte de preocupação da sociedade. Como exemplo disso são as notícias freqüentes sobre rebeliões e motins.

Neste contexto, este trabalho se propôs a analisar os níveis de satisfação e comprometimento dos servidores de um presídio do Distrito Federal com sua equipe de trabalho. Pois se espera que a partir desta pesquisa sejam apontados elementos que afetam significativamente os níveis de satisfação e comprometimento das equipes de trabalho de uma penitenciária e, por conseqüência, contribua para uma melhor compreensão das variáveis que afetam o desempenho das equipes ali presentes.

\subsection{Métodos e Técnicas de Pesquisa}

A investigação da pesquisa foi de natureza quantitativa, descritiva e correlacional. Os dados foram obtidos através de questionários aplicados com os servidores da organização em estudo, sob a forma de levantamento de dados (survey) e pesquisa documental. Estes dados foram analisados aplicando procedimentos de estatística descritiva.

\subsection{Estrutura e Organização da Monografia}

Com o intuito de atingir o objetivo proposto, esta pesquisa está estruturada em cinco capítulos. O primeiro capítulo é composto por sete seções. Na primeira é apresentada a contextualização do assunto; na segunda é descrito o problema a ser 
estudado; na terceira e na quarta o objetivo geral e os específicos; na quinta a justificativa do estudo; na sexta os métodos e técnicas de pesquisa; e na sétima a estrutura e a organização do trabalho. Já o segundo capítulo é composto pelo referencial teórico da pesquisa. Esse apresenta os conceitos teóricos, as definições e as características mais freqüentemente encontradas na literatura de equipes de trabalho, da satisfação e do comprometimento entre os membros da equipe. Esse capítulo tem como objetivo fundamentar, de acordo com a literatura cientifica da área, os principais constructos relacionados ao tema do estudo. Em seguida, o terceiro capítulo apresenta a metodologia utilizada para a obtenção das informações que subsidiaram a construção da análise. É dividido em cinco seções: a primeira delineia a pesquisa; a segunda faz uma breve caracterização da organização; a terceira aponta quem serão os participantes da pesquisa; a quarta descreve o instrumento utilizado para o levantamento de dados; e a quinta traz os procedimentos que serão realizados na obtenção e análise dos dados coletados. No quarto capítulo são apresentados e discutidos os resultados da pesquisa. Este é dividido em cinco seções: a primeira traz a descrição de aspectos sóciodemográficos dos participantes da pesquisa; a segunda os resultados sobre os níveis de satisfação e comprometimento das equipes de trabalho; a terceira os resultados das correlações que se mostraram significativas entre as variáveis satisfação e comprometimento e os aspectos sócio-demográficos dos participantes; a quarta os resultados da questão aberta e a quinta descreve as discussões sobre os resultados encontrados. E por último no quinto capítulo são apresentadas as conclusões da pesquisa, as suas principais contribuições, bem como as lacunas do estudo e sugestões de pesquisas futuras. 


\section{REFERENCIAL TEÓRICO}

Neste capítulo é apresentada a fundamentação teórica do trabalho realizado. Sua exploração abrange 0 estudo das equipes de trabalho como unidade de desempenho, a satisfação e o comprometimento dos membros das equipes nas relações interpessoais como critério de efetividade da equipe. Essa revisão de literatura busca esclarecer a importância das relações de trabalho entre os integrantes das equipes no atual contexto em que estão inseridas as organizações.

\subsection{Equipe de trabalho}

Com a chegada da globalização, desde a abertura dos mercados para a concorrência internacional, as organizações atuais a todo instante vem se deparando com novos desafios que devem ser superados através de esforços significativos para atingir patamares mais competitivos. Para responder adequadamente a esses desafios, surgiu um novo modelo de gestão. Neste novo modelo prevalece à visão do coletivo sobre o individual no qual a missão de cada indivíduo é preservar a harmonia do grupo (FREITAS, 2007); a cultura organizacional passou a ser orientada para a transformação de colaboradores em equipes (BERSOU; BERSOU, 1997); as organizações atuais passaram a buscar a maximização dos resultados de suas ações através da descentralização do poder (GUIMARÃES; MARTINS, 2008); passaram a estudar o incremento da diversidade da força de trabalho (PUENTE-PALACIOS, SEIDL; SILVA, 2008) e adotar as equipes de trabalho como unidades de desempenho (PUENTE-PALACIOS; BORGES-ANDRADE, 2005).

Puente-Palacios e Borges-Andrade (2005, p.58) afirmam que "nas equipes de trabalho, em decorrência da sua estrutura, a interação dos membros é imprescindível, pois os objetivos serão atingidos apenas a partir do esforço conjunto". Tendo como referência esta temática, estudiosos de diversos setores buscam alcançar maior grau de compreensão dos fatores que afetam o desempenho das equipes de trabalho. A esse respeito, Puente-Palacios e Carneiro (2005) levantaram a hipótese de que este interesse é decorrente da disseminação do uso de equipes de trabalho nas organizações para realizarem diversas atividades. 
Machado (1998, p.8) afirma que "mais do que avaliar o desempenho das pessoas é necessário se avaliar o desempenho das equipes de trabalho, pois na maioria das organizações, são por meio delas que os resultados estão sendo atingidos". Dessa maneira, através da pesquisa realizada por Freitas (2007) conclui-se que o estudo do trabalho em equipe se tornou importante na atualidade, uma vez que a competitividade, a tecnologia e a informação exigem esforços coordenados e pessoas que estejam comprometidas com a aprendizagem de todos os membros da equipe.

Para situar o trabalho em equipe no processo evolutivo profissional, vem primeiro o individuo; depois, o grupo; e, na ponta, a equipe. Maximiano (2000, p 20) acrescenta que "equipe de trabalho é um grupo de pessoas com objetivos comuns, que podem decidir como alcançá-los e que trabalham em uma área de autonomia bem definida". Mas existem outras definições como:

Uma equipe pode ser assim identificada quando entre seus membros esta
presente o conhecimento comum dos problemas e das ferramentas de trabalho, o
comprometimento com uma determinada causa, projeto ou problema e a
preocupação com a construção de um determinado ambiente de trabalho
(BERSOU; BERSOU, 1997, p. 6).

JÁ Sacomano Neto e Escrivão Filho (2000, p.140) consideram equipe como "um agrupamento de trabalhadores com diferentes responsabilidades funcionais, com objetivos estabelecidos, certa autonomia decisorial e multifuncionalidade dos postos de trabalho". São duas concepções diferentes, mas que de modo geral ambas compreendem a ideia de que equipe de trabalho é um conjunto de pessoas que unidas realizam suas tarefas em conformidade com um objetivo comum, de modo que o resultado não seja apenas a soma das habilidades de cada indivíduo.

Machado (1998, p.7), após analisar diversas definições sobre equipes de trabalho, concluiu que, ao longo do tempo, houve uma mudança de direção em relação a algumas características significativas do termo. Ou seja, "inicialmente, as definições privilegiavam aspectos mais formais da estruturação dos grupos, como por exemplo o tamanho e o direcionamento para objetivos específicos". Mas após 1990, os pesquisadores passaram a dar mais ênfase a "aspectos relacionais e contextuais". Sendo assim a autora define equipe de trabalho como:

Sistema de relações dinâmicas e complexas entre um conjunto de pessoas que se identificam a si próprias e são identificadas por outras pessoas dentro da 
organização como membros de um grupo relativamente estável, que interagem e compartilham técnicas, regras, procedimentos e responsabilidades, utilizadas para desempenhar tarefas e atividades com a finalidade de atingir objetivos mútuos. (MACHADO, 1998, p.7).

Bersou e Bersou (1997, p.6) afirmam que nas empresas onde se pratica uma cultura sedimentada, assim chamada por eles de "aquela que é derivada do armazenamento proveitoso das experiências vividas pela empresa ao longo de sua existência", os esforços de colaboração dos membros da equipe contribui para o aperfeiçoamento de cada um e da equipe como um todo, a partir de uma situação global de desenvolvimento. Conclui-se no estudo que empresas que utilizam este tipo de cultura transformam grupos de colaboradores em verdadeiras equipes de trabalho, pois, segundo os autores, estes grupos trabalham de forma conjunta. Como por exemplo: pensam juntos sobre a identificação dos problemas; neles as criticas são equilibradas, justas e acima de tudo apresentadas com respeito entre as partes; os objetivos individuais de trabalho são bem estabelecidos; o ambiente é de cordialidade e de reconhecimento; eles procuram as causas dos problemas e menos os culpados e, sobretudo, são mais comprometidas com o trabalho. Nestas condições as equipes não receiam em apresentar suas contribuições e o fator de alavancagem da equipe aumenta consideravelmente.

Peduzzi (2001, p.106) elaborou conceito e tipologia de trabalho em equipe, bem como critérios para o seu reconhecimento. Para a autora "o trabalho em equipe consiste numa modalidade de trabalho coletivo que se configura na relação recíproca entre as intervenções técnicas e a interação dos agentes". Ela também reconheceu duas modalidades de trabalho em equipe denominando-as de equipe agrupamento e equipe integração. Peduzzi define que "na equipe agrupamento, há uma justaposição de ações e agrupamento de agentes, enquanto que na equipe integração, ocorre a articulação das ações e a interação dos agentes". Conclui-se no estudo que o critério que pode auxiliar no reconhecimento das equipes de trabalho enquanto pertencentes a uma das modalidades são: a comunicação entre os profissionais do trabalho em equipe, a formulação de um projeto assistencial comum, a flexibilidade da divisão do trabalho e a autonomia técnica. Tudo isso decorre da relação recíproca entre trabalho e interação.

Entretanto coordenar um grupo de pessoas é na maioria dos casos algo bastante difícil. É inevitável deparar-se com os diferentes pensamentos, formas de agir e 
conceber as idéias, pois motivações diversas circulam num grupo de trabalho. Mas segundo Cardoso (2009, p.15), em meio a tantas peculiaridades, no entanto, "é preciso convergir esforços para alcançar objetivos e metas que sejam comuns a todos e que se traduzam na finalidade do próprio grupo".

Sacomano Neto e Escrivão Filho (2000, p.144) afirmam que "nas empresas estudadas por eles foram inúmeros os benefícios apontados com a utilização das equipes, estando entre eles o trabalho mais eficiente e motivador, e a tomada de decisão mais flexível". Os autores não deixam de salientar a necessidade de uma maior preocupação com as melhorias das condições sociais dos trabalhadores que participam deste movimento, tanto nos aspectos financeiros como de relacionamento, entendimento e humanização das relações de trabalho. Como consequência deste resultado, conclui-se também que ambientes de cordialidade e de reconhecimento são elementos fundamentais na construção de equipes de trabalho.

O estudo de Puente-Palacios (2002) foi norteado pela definição oferecida por Machado (1998) para equipe de trabalho. Como o presente estudo irá utilizar como instrumento de pesquisa a Escala de Satisfação com a equipe de trabalho validada por Puente-Palacios (2002) e outros estudos desenvolvidos pela mesma autora, este também será orientado pela definição de Machado sobre equipe de trabalho.

Puente-Palacios (2002, p.55) afirma que "o desempenho dos grupos de trabalho envolve um complexo sistema de ações e interações que ocorrem antes, durante e após a realização das tarefas e afetam a efetividade". Pesquisas da área, aqui já citadas, apontam que variáveis referentes às relações pessoais têm papel fundamental no desempenho da organização. Como exemplo destas pesquisas, podemos citar Machado (1998, p.8) que afirma que "mais do que avaliar o desempenho das pessoas, é necessário se avaliar o desempenho das equipes de trabalho, pois, na maioria das organizações, são por meio delas que os resultados estão sendo atingidos

Nas ultimas décadas os pesquisadores deixaram de enfocar o termo conceitual restrito de "resultado do trabalho" e passaram a usar um termo mais amplo: a efetividade. Para Machado (1998, p.11) a utilização do termo efetividade institui uma "tentativa de avanço conceitual na análise dos produtos gerados pelas equipes de trabalho, incorporando tanto os aspectos dinâmicos e complexos de desempenho, 
quanto os aspectos mais objetivos relacionados aos resultados". Ou seja, Machado (1998, p.38) afirma que:

Embora não haja uniformidade, a efetividade tem sido medida por meio dos resultados produzidos pela equipe (qualidade, quantidade, tempo, satisfação dos clientes) e das consequências que o trabalho em equipe tem para seus membros (satisfação e capacidade de trabalho conjunto no futuro).

Discutindo a respeito da efetividade, Van der Vegt (1998 apud SOUZA, 2006, p.61) afirma que "a satisfação e o comprometimento com a equipe podem ser consideradas variáveis primárias nos resultados afetivos do domínio das equipes de trabalho". O autor defende que respostas afetivas relacionadas à equipe são diferentes daquelas relativas à organização. Pois segundo o mesmo, "embora a organização constitua o meio ambiente em que o desempenho ocorre, a relação mantida com o indivíduo é mais distante ou diferente daquela mantida entre o membro e a equipe à qual pertence".

Puente-Palacios e Borges-Andrade (2005, p.64) também defendem que o comprometimento organizacional tem-se revelado juntamente com satisfação com a equipe de trabalho um aspecto importante na concepção de bem-estar no trabalho e de melhor desempenho na organização.

Uma vez tendo descrito de maneira resumida as definições e a natureza das equipes de trabalho, a seguir são abordadas algumas definições sobre Satisfação e Comprometimento com a equipe, com o objetivo de estabelecer os elementos apontados, por diversos autores, como determinantes de um melhor desempenho da organização.

\subsection{Satisfação com a equipe}

O desempenho das equipes de trabalho está intimamente relacionado com a satisfação dos seus membros com a mesma. Gladstein (1984 apud PUENTE PALACIOS, 2002, p.21) considera a satisfação como uma reação afetiva positiva em relação à equipe de trabalho, resultante da forma como os membros se relacionam e trabalham juntos e pode ser utilizada como critério de efetividade da equipe. Esta definição irá orientar esta pesquisa. 
Segundo Siqueira e Gomide Jr. (2004, p. 307) "a satisfação tem sido estudada desde as décadas iniciais do século passado exercendo atração sobre estudiosos tanto de Psicologia Organizacional e do Trabalho como sobre gestores e pesquisadores de comportamento organizacional". Mas há controvérsias quanto a sua definição, sua essência psicológica (afetiva ou cognitiva) e dimensões. De acordo com esses autores, a maior parte das definições considera a natureza afetiva da satisfação. Mas os mesmos apontam divergências em relação às suas dimensões. Pois, eles afirmam que existe uma linha teórica que a considera como sendo um construto multidimensional, definido como "um conjunto de reações específicas a vários componentes do trabalho (trabalho, chefia, colegas, salário, equipe), capazes de desencadear no indivíduo diferentes graus de satisfação e insatisfação". E uma linha unidimensional que concebe a satisfação como "uma atitude geral ante o trabalho como um todo, não sendo, portanto, relevante especificar as reações específicas dos indivíduos”.

Puente-Palacios e Borges-Andrade (2005, p.83) afirmam que "a satisfação é o vínculo afetivo positivo estabelecido com a unidade de desempenho, como resultado de experiências favoráveis vivenciadas ao longo do trabalho". Ou seja, os autores concluíram que as experiências positivas do trabalho em equipe elevam a probabilidade do surgimento de vínculos afetivos com a equipe e que isso deixa os membros mais satisfeitos.

Já para Souza (2006, p.05) a satisfação pode ser caracterizada como sendo "um construto multidimensional, definido como um conjunto de reações específicas a vários componentes do trabalho (trabalho, chefia, colegas, salário, equipe), capazes de desencadear no indivíduo diferentes graus de satisfação e insatisfação".

Ainda no trabalho de Puente-Palacios e Borges-Andrade (2005, p. 64), assim como já havia sido defendido pela Puente-Palacios (2002), a satisfação dos membros das equipes de trabalho é novamente considerada como indicador da efetividade. Pode-se concluir que, para vários pesquisadores que estudaram o assunto, a efetividade da equipe é compreendida com base na observação de três critérios fundamentais: os resultados produtivos do trabalho em si, a sobrevivência da equipe e a satisfação dos membros. Os autores do artigo em questão, após revisarem a literatura da área, mostraram que "a satisfação é um indicador freqüentemente adotado nestes trabalhos, seja de maneira isolada ou associada a 
julgamentos" (PUENTE-PALACIOS, 2002, p.44); e consideraram duas variáveis como explicativas da satisfação: a Interdependência das equipes, como característica dos grupos, e a crença na efetividade das equipes, como característica dos grupos.

Outros estudos apontam a relação entre a satisfação da equipe com a interdependência de resultados ou de tarefas, com o comprometimento com o grupo de trabalho, a diversidade dos membros e da complexidade do trabalho (MACHADO, 1998; SOUZA, 2006; PUENTE-PALACIOS, 2008; PUENTEPALACIOS; SEIDL; SILVA, 2008). De acordo com esses estudos, grupos com alta interdependência de resultados tendem a apresentar maiores índices de satisfação em situações de alta interdependência de tarefas. Da mesma forma que altos níveis de complexidade do trabalho indicam níveis mais altos de satisfação com a equipe.

Baseado nestes estudos, a seguir são abordadas algumas definições sobre comprometimento com a equipe de trabalho, com o objetivo de esclarecer o uso esta variável como um dos fatores determinante da efetividade das equipes.

\subsection{Comprometimento com a equipe de trabalho}

As interações do trabalhador no seu meio de trabalho com seus colegas geram vínculos afetivos entre os membros da organização. Estes vínculos produzem reflexos no comprometimento do trabalhador com a organização e o comprometimento deste com sua equipe de trabalho. Segundo Siqueira e Gomide Jr. (2004), as pessoas estabelecem relações com as organizações onde trabalham com intuito de satisfazer suas necessidades, sejam elas pessoais, profissionais ou familiares. Durante esse processo, diferentes vínculos são estabelecidos entre ambos.

Guimarães e Martins (2008) afirmam que conhecer melhor esse fenômeno social é estratégico para a gestão de pessoas e políticas no meio organizacional, uma vez que, atualmente, as organizações vivem em ambientes instáveis, enfrentando desafios e problemas inéditos que requerem soluções inovadoras. Conclui-se na pesquisa que nesse contexto turbulento, as organizações necessitam contar com funcionários comprometidos com o trabalho. 
Bastos (1992, p.32), baseado em estudos internacionais, aponta que o comprometimento organizacional é "a força relativa que une o indivíduo a uma organização particular". O autor enfatizava a busca das empresas por maior qualidade e produtividade, e em atrair e manter os profissionais mais competentes. Esta definição guiará esta pesquisa.

Medeiros et al. (2003) concluem que nos últimos anos não tem sido diferente; as empresas têm despendido grande esforço na busca e retenção de pessoas mais qualificadas e que estejam propensas a se comprometer com as organizações. Os processos de recrutamento e seleção de pessoal tentam, mais do que nunca, prover as empresas com indivíduos comprometidos e com desempenho superior. Ele afirma que aliado ao dispêndio dos processos de seleção, os programas de retenção de talentos acarretam custos cada vez maiores, decorrentes dos benefícios e salários oferecidos pelas organizações.

Ainda sobre a pesquisa de Medeiros et al. (2003), os autores analisaram a agenda da pesquisa do comprometimento, estabelecidas por diversos autores considerados clássicos nesse campo na literatura brasileira através dos 34 trabalhos publicados nos Encontros Anuais da ANPAD entre 1994 e 2002 sobre o assunto $\mathrm{e}$ apresentaram os avanços que 0 estudo do comprometimento organizacional obteve no Brasil. Eles concluíram que em 1992, poucos eram os trabalhos sobre comprometimento organizacional no país e as discussões sobre o assunto tinham que usar como referência à literatura estrangeira. Mas hoje a situação é bem diferente, pois existem no Brasil sólidas pesquisas na área. $\mathrm{Na}$ década de 90 diversas pesquisas abordavam o comprometimento como um construto multidimensional, tentando entender os indivíduos e seu vínculo com a organização de maneira mais complexa. Mas hoje a literatura sobre comprometimento possui múltiplos focos, como organização e carreira, e bases, como afetiva, normativa e instrumental.

Recentemente Cropanzano et al. (2005 apud GUIMARÃES ; MARTINS, 2008, p.61) também estudaram o comprometimento com foco na equipe e ressaltaram "a importância de diferenciar esse tipo de comprometimento do comprometimento com a organização, pois, aparentemente, o empregado estabelece diferentes vínculos com esses dois aspectos presentes em sua vida profissional". 
O estudo de Puente-Palácios et al. (2005), sugere que o comprometimento afetivo com a equipe tenha como foco a equipe de trabalho mais próxima do empregado, e que este comprometimento se estabelece a partir da identificação e do envolvimento do sujeito com sua equipe. As principais abordagens deste estudo são: crença e aceitação dos objetivos e valores da equipe; esforço para o sucesso dela e vontade de permanecer nela.

Baseada na sugestão de Puente-Palácios et al. (2005), esta pesquisa irá analisar os níveis de satisfação e comprometimento dos servidores de uma penitenciária com a sua respectiva equipe. Serão consideradas como "equipe de trabalho" aquelas cujos servidores trabalham na mesma seção ou no mesmo bloco, ou seja, aqueles que se relacionam diretamente na hora de executar suas atividades. 


\section{MÉTODOS E TÉCNICAS DE PESQUISA}

Neste capítulo, será descrito o método utilizado para alcançar os objetivos propostos para o presente trabalho. Ele está organizado da seguinte forma: (a) delineamento da pesquisa; (b) caracterização da organização; (c) população e amostra; (d) caracterização dos instrumentos de pesquisa (e) procedimentos de coleta e análise de dados.

\subsection{Tipo e descrição geral da pesquisa}

Sousa, Driessnack, e Mendes (2007, p.503) em seu artigo sobre desenhos de pesquisa quantitativa, concluíram que "a pesquisa quantitativa frequentemente quantifica relações entre variáveis - a variável independente ou preditiva e a variável dependente ou resultado". Os autores também afirmam que "estudos correlacionais descritivos descrevem variáveis e as relações que ocorrem naturalmente entre as mesmas". Do mesmo modo Creswell (2007, p.47) afirma que "a pesquisa quantitativa inclui uma quantidade substancial de literatura no começo de um estudo para dar direção às questões ou hipóteses de pesquisa".

Deste modo, a investigação nesta pesquisa foi de natureza quantitativa, descritiva e correlacional. Os dados foram obtidos através de levantamento de dados "survey" com meio de questionários auto-explicativos respondidos pelos servidores da organização em estudo para verificar os níveis de satisfação e comprometimento destes com suas equipes de trabalho. A coleta de dados secundários sobre a empresa foi obtida através de documentos levantados na própria organização.

\subsection{Caracterização da organização}

O Sistema Penitenciário do Distrito Federal está, atualmente, ligado à Subsecretaria do Sistema Penitenciário (SESIPE) e esta por sua vez está integrada à estrutura administrativa da Secretaria de Segurança Pública do Distrito Federal. Estão subordinadas à SESIPE seis unidades prisionais, a saber: Centro de Detenção Provisória (CDP), Centro de Internamento e Reeducação (CIR), Centro de Progressão Penitenciária (CPP), Penitenciária I do Distrito Federal (PDF I), 
Penitenciária II do Distrito Federal (PDF II), Penitenciária Feminina do Distrito Federal (PFDF) e uma unidade operacional, chamada Diretoria Penitenciária de Operações Especiais (DPOE).

Esta pesquisa foi desenvolvida em uma das unidades prisionais, uma penitenciária do Distrito Federal, inaugurada em 21 de maio de 2001 e que tem sua estrutura física dividida em: Prédio da administração, portão principal e quatro blocos (D, E, F e G). Ela possui três áreas de trabalho bem definidas: os servidores que trabalham nas seções administrativas cumprindo regime de expediente de segunda a sexta, das $9 \mathrm{~h}$ às $16 \mathrm{~h}$ e que são responsáveis pela parte administrativa da penitenciária; os servidores dos quatro blocos e do portão principal que trabalham cumprindo regime de plantão, de $24 \mathrm{~h}$ de trabalho por $72 \mathrm{~h}$ de descanso, com horário de entrada e saída às $9 \mathrm{~h}$ e que são responsáveis pelo serviço operacional, ou seja, responsáveis pela tutela, vigilância e escolta de presos e ainda controlam a entrada e a saída de pessoas no sistema; e ainda os funcionários que trabalham na parte da limpeza e manutenção da penitenciária (todos terceirizados), onde cada trabalhador é responsável por uma área do prédio (estes últimos não foram estudados pois não trabalham em equipe).

A penitenciária, diferentemente das demais unidades prisionais existentes nos outros Estados, é administrada e dirigida por um policial civil investido no cargo de Delegado. A mesma até fevereiro de 2009 tinha em seu quadro funcional: policias civis, policiais militares e bombeiros, e os servidores de carreira administrativa do Governo do Distrito Federal (GDF). Contudo, no final do mesmo mês passaram a integrar o respectivo quadro os Técnicos Penitenciários, cargo vinculado à Secretaria de Segurança Pública do GDF criado recentemente para suprir a demanda de servidores e para substituir os policiais que trabalham no sistema.

Os servidores que trabalham no regime de plantão são divididos em quatro equipes denominadas de: ALFA, BRAVO, CHARLIE e DELTA. Estas se revezam de acordo com a escala do plantão.

A estrutura administrativa da penitenciária está organizada conforme consta no Anexo A. 


\subsection{População e amostra}

A penitenciária em estudo tem hoje 263 servidores trabalhando em regime de expediente ou plantão. Destes 108 servidores estão distribuídos em uma das 17 seções do expediente e os outros 155 estão distribuídos em uma das quatro equipes do plantão. É necessário salientar que cada equipe do plantão se subdivide em cinco equipes menores, onde quatro são responsáveis por cada um dos blocos da penitenciária e a outra pelo portão principal.

É necessário salientar que no dia do levantamento dos dados alguns servidores encontravam de férias, abono, em serviço externo ou de férias. Por isso foram distribuídos 182 questionários aos membros das equipes presentes na hora da coleta. Desses dois foram devolvidos em branco, dois foram excluídos por terem deixado de responder as variáveis sócio-demográficas e outros dois foram excluídos por terem dado a mesma resposta a todas as perguntas das duas escalas. "A invariância absoluta das respostas, que sugere falta de interesse por oferecer informações verdadeiras, sustentou a decisão de não incluí-los no banco de dados" (PUENTE-PALACIOS, 2002, p.114). Portanto foram considerados válidos 176 questionários o que corresponde a $67 \%$ da população.

\subsection{Caracterização dos instrumentos de pesquisa}

O questionário utilizado para o levantamento de dados na presente pesquisa era composto de três partes: na primeira foi feita uma breve apresentação do trabalho com informações sobre o objetivo principal da pesquisa e de como os participantes deveriam proceder no momento de responder o questionário; a segunda parte é composta pela escala de satisfação com a equipe de trabalho e pela escala de comprometimento das equipes de trabalho; na terceira e última parte foram incluídas questões sócio-demográficas e uma questão aberta.

A mensuração dos níveis de satisfação com a equipe de trabalho realizou-se a partir da aplicação da escala que foi modificada e adaptada para a realidade nacional e validada por Puente-Palacios (2002) extraída do instrumento desenvolvido por Van der Vegt et al. (1999 apud PUENTE-PALACIOS, 2002, p.118). Este instrumento é composto por cinco itens a serem respondidos, em uma escala 
Likert de concordância de cinco pontos, no qual 1 correspondia a "discordo totalmente" e 5 a "concordo totalmente".

Já para a mensuração dos níveis de comprometimento com a equipe foi utilizada a escala desenvolvida por Caixeta e Puente-Palacios (2005). A escala constituiu uma adaptação, ao contexto de equipes, do instrumento de comprometimento organizacional desenvolvido por Bastos (1992) que foi modificado de maneira tal que o conteúdo dos itens passasse a se referir à equipe ao invés da organização. $O$ novo instrumento ficou composto por nove itens que descrevem atitudes do trabalhador em relação a seu comprometimento com a equipe de trabalho. Os itens foram respondidos por meio de uma escala Likert, que variava de 1 "discordo totalmente" até 5 "concordo totalmente".

Ambas as escalas são validadas e os itens são representados por um único fator (escalas unifatoriais).

$\mathrm{Na}$ última parte do questionário foram inseridos oito itens relacionados às informações sócio-demográficas e funcionais dos participantes da pesquisa, a fim de caracterizar os participantes da pesquisa, tais como: sexo, regime de trabalho, seção ou equipe do plantão, idade, tempo de serviço na organização, cargo e grau de escolaridade. Uma última questão aberta foi incluída, destinada aos comentários ou sugestões dos respondentes.

\subsection{Procedimentos de coleta e de análise de dados}

Os questionários foram aplicados pela autora da pesquisa. Esta visitou pessoalmente todas as seções e as equipes do plantão, onde os questionários foram entregues a todos os membros das equipes que se encontravam no seu local de trabalho na hora da aplicação do questionário. A visita foi previamente agendada com a administração da penitenciária. No momento da coleta de dados foi explicado aos participantes o objetivo da pesquisa, o seu caráter anônimo e o fato de ser voluntária a participação. Com o objetivo de conseguir um maior número de questionários respondidos, a autora distribuiu e aguardou no local de aplicação o preenchimento do instrumento pelos integrantes das equipes. 
Para a realização das análises dos dados coletados na amostra composta por 176 respondentes, os dados dos questionários foram inseridos no software Statistical Package for Social Sciences (SPSS), versão 18.0. Foram calculadas estatísticas descritivas (média e desvio padrão) para descrever os resultados em relação aos fatores satisfação e comprometimento com a equipe de trabalho. $E$ anteriormente a esses cálculos, foram feitas inversões dos resultados dos dois itens negativos que fazem parte da escala do comprometimento.

Também foram realizadas correlações de Pearson para verificar a existência de relação entre os referidos fatores e as variáveis sócio-demográficas: idade, sexo, regime de trabalho, grau de escolaridade e tempo de serviço. E por último, foram distribuídas as observações da questão aberta em sete categorias criadas para melhor interpretação dos resultados.

Os resultados dessas análises encontram-se no capítulo a seguir. 


\section{RESULTADOS E DISCUSSÃO}

Os resultados da pesquisa junto aos servidores da penitenciária são apresentados da seguinte forma: primeiramente, a caracterização do perfil dos respondentes através da descrição de aspectos sócio-demográficos. Em seguida, são descritas as médias e os desvios padrão dos fatores satisfação e comprometimento com a equipe de trabalho. Também serão relatadas as médias e os desvios padrão de cada item que compõe as duas escalas e serão apresentadas as correlações que se mostraram significativas entre as variáveis que representam satisfação e comprometimento e os aspectos sócio-demográficos.

\subsection{Descrição de aspectos sócio-demográficos}

Em relação à variável gênero, das 176 pessoas que responderam o questionário $128(72,7 \%)$ são do sexo masculino e $48(27,3 \%)$ do sexo feminino. Dos respondentes homens 38 trabalham no expediente e 90 no plantão. Já com relação às mulheres, das 48 respondentes 30 trabalham no expediente e 18 no plantão. Esses dados são compatíveis com a realidade da penitenciária, já que a maioria das servidoras do sistema trabalha em regime de expediente.

A organização em estudo tem no total 263 servidores que trabalham em regime de plantão ou expediente. Dos 108 servidores que trabalham em regime de expediente em uma das 17 seções de penitenciária, 68 servidores participaram da pesquisa. Os resultados são apresentados a seguir:

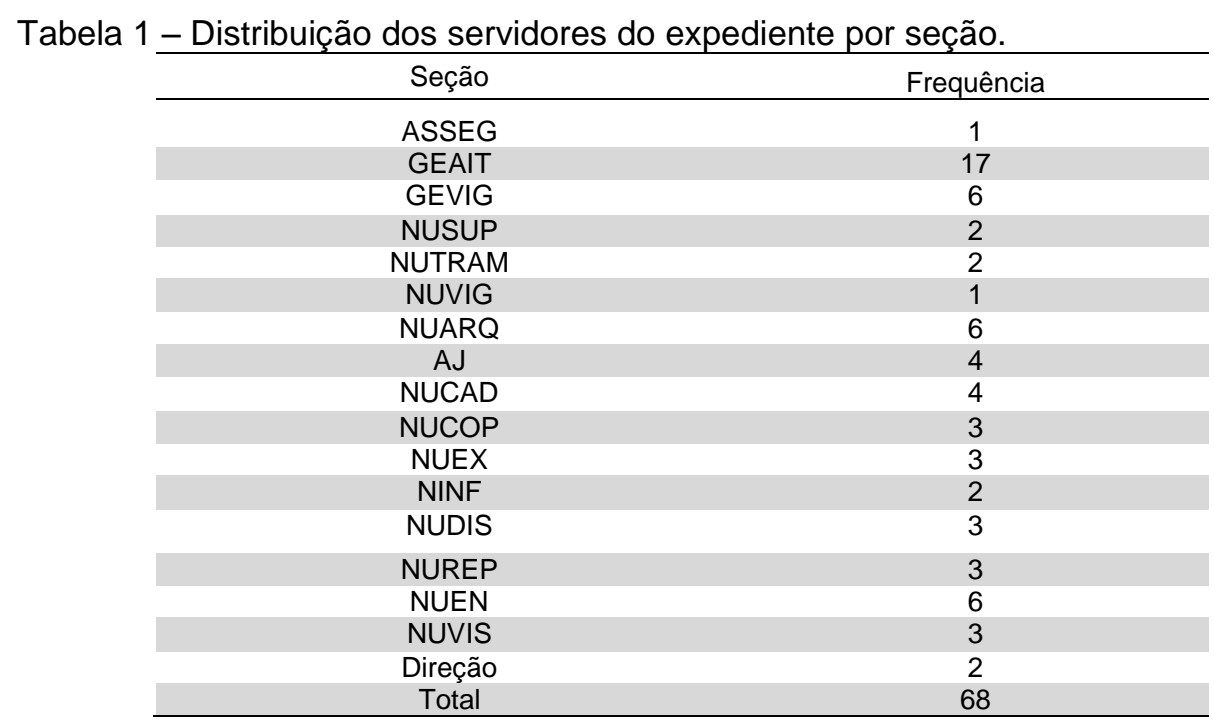


$\mathrm{Na}$ composição da amostra por regime de trabalho, dos 155 servidores que trabalham em regime de plantão, 108 (70\% do total) participaram da pesquisa. A equipe que mais participou foi a BRAVO (33 pessoas) e a menor participação foi da equipe ALFA (22 pessoas), como pode ser visto no Gráfico a seguir.

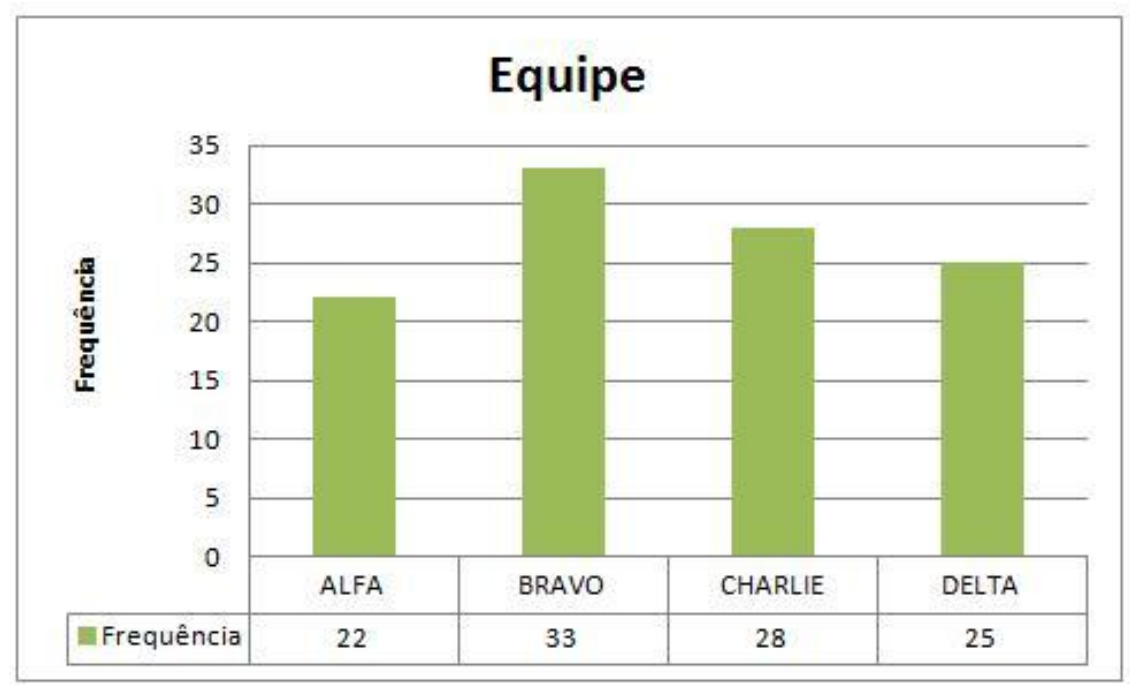

Gráfico 1. Frequência de participantes por equipe do plantão.

No arranjo da amostra por categoria profissional, os Técnicos Penitenciários destacaram-se com o maior número de participantes (72,2\%) e em segundo lugar vem os Agentes Penitenciários (13,6\%). Já com relação à idade dos profissionais, a maioria dos respondentes tinha entre 26 e 30 anos $(43,8 \%)$.

Tabela 2 - Distribuição dos servidores participantes, agrupados em cargo e idade.

\begin{tabular}{cccc}
\hline Variável & Cargo & Frequência & Porcentagem \\
\hline \multirow{4}{*}{ Cargo } & Técnico Penitenciário & 127 & 72,2 \\
& Policial Militar & 6 & 3,4 \\
& Agente Penitenciário & 24 & 13,6 \\
& Outros & 19 & 10,8 \\
& Total & 176 & 100 \\
\hline \multirow{4}{*}{ Idade } & 18 a 25 anos & 42 & 23,9 \\
& 26 a 30 anos & 77 & 43,8 \\
& 31 a 35 anos & 29 & 16,5 \\
& 36 a 40 anos & 12 & 6,8 \\
41 a 45 anos & 7 & 4,0 \\
46 a 50 anos & 7 & 4,0 \\
& Acima de 50 anos & 2 & 1,1 \\
& Total & 176 & 100 \\
\hline
\end{tabular}


No que se refere ao tempo de serviço, $72,7 \%$ da amostra têm até um ano de serviço na organização. E em relação ao nível de escolaridade, houve predomínio de profissionais com ensino superior $(51,1 \%)$ ou que estejam concluindo o ensino superior $(23,3 \%)$, como mostra a tabela a seguir.

Tabela 3 - Distribuição dos servidores em relação ao tempo de serviço e o grau de escolaridade.

\begin{tabular}{cccc}
\hline Variável & Tipo & Frequência & Porcentagem \\
\hline & Até 1 ano & 128 & 72,7 \\
& Acima de 1 até 5 anos & 15 & 8,5 \\
& Acima de 5 até 10 anos & 20 & 11,4 \\
Tempo de & Acima de 10 até 15 anos & 3 & 1,7 \\
& Acima de 15 até 20 anos & 3 & 1,7 \\
& Acima de 20 anos & 7 & 4,0 \\
& Total & 176 & 100,0 \\
\hline Grau de & Ensino médio & 43 & 24,4 \\
Escolaridade & Superior incompleto & 41 & 23,3 \\
& Superior & 90 & 51,1 \\
& Mestrado & 2 & 1,1 \\
\hline
\end{tabular}

Caracterizada a amostra, destacam-se a seguir os resultados das respostas aos dois instrumentos que integravam o questionário.

\subsection{Níveis da Satisfação e Comprometimentos das equipes}

Baseado na utilização da Escala de Satisfação com a Equipe de Trabalho e da Escala de Comprometimento com a Equipe de Trabalho, escalas unifatoriais, são descritas na Tabela 4 a média e o desvio padrão destes fatores.

Tabela 4 - Média e desvio padrão das Escalas satisfação e comprometimento com a equipe de trabalho.

\begin{tabular}{ccc}
\hline Fatores & Média & Desvio Padrão \\
\hline Satisfação com a equipe de trabalho & 4,48 & 0,62 \\
Comprometimento com a equipe de trabalho & 4,36 & 0,66 \\
\hline
\end{tabular}


Observa-se que a Satisfação com a equipe de trabalho obteve a maior média $(M=4,48)$ que, de acordo com a escala Likert utilizada, se situou entre pouca concordância (4) e concordância total (5). Porém este fator teve o desvio padrão superior ao desvio padrão do fator Comprometimento indicando variabilidade de percepção entre os sujeitos da pesquisa. Já o fator Comprometimento, após a inversão dos dois itens negativos, obteve a média $(M=4,36)$ que, de acordo com a escala Likert utilizada, também se situou entre pouca concordância (4) e concordância total (5).

A seguir, para uma melhor compreensão destes resultados serão relatados em modo decrescente de média, os resultados de cada item dos dois fatores que compõem as escalas estudadas.

Tabela 5 - Média e desvio padrão dos itens que compõem o fator Satisfação com a equipe de trabalho.

\begin{tabular}{rlrr}
\hline Itens & \multicolumn{1}{c}{ Descrição dos itens } & Média & $\begin{array}{r}\text { Desvio } \\
\text { Padrão }\end{array}$ \\
\hline 4 & $\begin{array}{l}\text { Sinto-me bem a respeito do relacionamento que mantenho com os } \\
\text { membros da minha equipe de trabalho. }\end{array}$ & 4,75 & 0,55 \\
2 & $\begin{array}{l}\text { Tenho sentimentos positivos sobre a forma como trabalhamos juntos } \\
\text { na minha equipe. }\end{array}$ & 4,57 & 0,68 \\
1 & $\begin{array}{l}\text { Em relação aos membros da minha equipe de trabalho, eu sinto } \\
\text { confiança de que manteremos boas relações no futuro. }\end{array}$ & 4,52 & 0,71 \\
\hline 3 & $\begin{array}{l}\text { Estou satisfeito com a forma em que trabalhamos juntos na minha } \\
\text { equipe. }\end{array}$ & 4,41 & 0,86 \\
\hline 5 & Confio completamente nos membros da minha equipe. & 4,14 & 1,06 \\
\hline
\end{tabular}

Considerando os cinco itens da escala de Satisfação que integram o cálculo geral do escore, foram identificados os itens que isoladamente apresentavam o maior e menor escore médio de satisfação entre os servidores da penitenciária e os membros de suas equipes. $O$ item que apresentou a maior média e ao mesmo tempo o menor desvio padrão foi o item 4 "sinto-me bem a respeito do relacionamento que mantenho com os membros da minha equipe de trabalho" ( $\mathrm{M}=$ $4,75 ; \mathrm{DP}=0,55)$. Já o item que apresentou a menor média de satisfação e o maior desvio padrão foi o item 5 "Confio completamente nos membros da minha equipe " $(M=4,14 ; \mathrm{DP}=1,06)$. Assim, embora os níveis de satisfação da equipes sejam altos, alguns participantes da pesquisa não confiam completamente nos seus companheiros de equipe. 
Já com relação aos resultados de cada item que compõem o fator Comprometimento, os valores podem ser vistos na Tabela a seguir.

Tabela 6 - Média e desvio padrão dos itens que compõem o fator Comprometimento com a equipe de trabalho.

\begin{tabular}{clcc}
\hline Itens & \multicolumn{1}{c}{ Descrição dos itens } & Média & $\begin{array}{c}\text { Desvio } \\
\text { Padrão }\end{array}$ \\
\hline 6 & Eu realmente me interesso pelo destino da equipe a qual pertenço. & 4,75 & 0,63 \\
5 & $\begin{array}{l}\text { Eu me sinto contente por ser parte desta equipe, comparando com as } \\
\text { outras que conheço. }\end{array}$ & 4,55 & 0,89 \\
3 & $\begin{array}{l}\text { Eu me sinto orgulhoso dizendo às pessoas que sou parte da minha } \\
\text { equipe de trabalho. }\end{array}$ & 4,48 & 0,83 \\
1 & $\begin{array}{l}\text { Conversando com amigos, eu sempre me refiro a minha equipe de } \\
\text { trabalho como uma grande unidade para a qual é ótimo trabalhar }\end{array}$ & 4,28 & 0,97 \\
7 & A minha equipe é a melhor de todas para se trabalhar. & 4,17 & 1,06 \\
4 & $\begin{array}{l}\text { A minha equipe de trabalho realmente inspira o melhor em mim, para } \\
\text { o progresso no desempenho das minhas atividades }\end{array}$ & 4,16 & 0,94 \\
2 & $\begin{array}{l}\text { Eu julgo que os meus valores são muito similares aos valores } \\
\text { defendidos pela equipe de trabalho a qual pertenço. }\end{array}$ & 3,97 & 1,05 \\
9 & Eu sinto pouca lealdade da equipe em que trabalho. & 1,85 & 1,23 \\
\hline 8 & Decidir trabalhar nesta equipe foi um erro de minha parte. & 1,23 & 0,71 \\
\hline
\end{tabular}

Avaliando agora os nove itens da escala do Comprometimento que integram o cálculo geral do escore, também foram identificados os itens que isoladamente apresentavam o maior e a menor média e desvio padrão. $\mathrm{O}$ item que apresentou a maior média e ao mesmo tempo o menor desvio padrão foi o item 6 "eu realmente me interesso pelo destino da equipe a qual pertenço" $(M=4,75$; $D P=0,63)$. O item com menor média foi o item 2 "eu julgo que os meus valores são muito similares aos valores defendidos pela equipe de trabalho a qual pertenço".

Em relação aos dois itens negativos, as médias se situaram entre 1 ( discordo totalmente) e 2 (discordo pouco) indicando que os respondentes discordam com a afirmação. E significando que eles sentem lealdade e que não acham, que foi um erro trabalhar na equipe a qual pertencem.

\subsection{Resultado das Correlações}

Uma vez descritas às características gerais das variáveis envolvidas no estudo, foi realizada análise estatística para se descobrir as correlações existentes entre as variáveis satisfação e comprometimento e os aspectos sócio-demográficos. 
As correlações significativas encontradas sobre o fator Satisfação estão relacionadas ao sexo e ao regime de trabalho dos participantes da pesquisa.

Os resultados revelaram correlação negativa entre os escores da satisfação e a variável sexo $(r=-0,268 ; p<0,001)$. Ou seja, as mulheres são menos satisfeitas, do que os homens, com sua equipe de trabalho. Já em relação ao regime de trabalho, a correlação foi positiva $(r=0,161 ; p<0,033)$ isso quer dizer que as equipes da plantão são mais satisfeitas que as do expediente.

Em relação ao fator Comprometimento foram identificadas correlações significativas entre fator e as variáveis: sexo e regime de trabalho. Novamente as mulheres são menos comprometidas com sua equipe de trabalho $(r=-0,311 ; p<$ 0,0001 ) e o pessoal do plantão é mais comprometido com a equipe que o pessoal do expediente $(r=0,257 ; p<0,0001)$.

\subsection{Resultado da questão aberta}

Ao todo 20 pessoas fizeram observações na questão aberta. Com essas respostas foram criadas sete categorias para melhor interpretação dos resultados. As categorias são: identificação com o serviço, bom relacionamento interpessoal, falta de espírito de equipe, insatisfação com o Governo, prematuridade da equipe, satisfação com o líder e má distribuição do trabalho. Conclui-se que a maioria dos respondentes da questão são servidores que, de alguma forma, não estão satisfeitos com suas equipes ou com o Governo, pois a categoria "insatisfação com o Governo" teve seis (30\%) das respostas e em segundo lugar ficou a categoria "falta de espírito de equipe" com quatro respostas (20\%).

Os resultados da análise dessas questões estão melhores descritos na discussão do presente trabalho.

\subsection{Discussão}

Em um primeiro momento, por se tratar de um estudo sobre equipes de trabalho, é necessário considerar o que faz da amostra em análise uma equipe.

Entre os 176 servidores da penitenciária que participaram deste estudo, havia Técnicos Penitenciários, Agentes Penitenciários, Técnicos na área de saúde, 
Policiais Militares, dentre outros. Estes devem, em maior ou menor grau, interagir de maneira a obter resultados favoráveis de desempenho, sejam estes: tutela, disciplina, saúde, vigilância e escolta dos internos. Observa-se, então, que os participantes mantêm relações dinâmicas e complexas com seus colegas de trabalho.

Além disso, como o trabalho final de um servidor do bloco depende do trabalho do controlista (pessoa responsável pela entrada do bloco), que também está relacionado às atividades executadas pelo supervisor, nota-se que tais profissionais compartilham técnicas, regras e procedimentos com o objetivo de alcançar uma meta que lhes é comum, no caso, distribuir as refeições aos presos, por exemplo. Uma vez que as células de trabalho com as quais a pesquisa foi desenvolvida atendem às características propostas por Machado (1998), pode-se afirmar que são, de fato, equipes de trabalho.

O presente trabalho teve como segundo requisito avaliar os níveis de satisfação e comprometimento com a equipe de trabalho dos servidores da penitenciária, já que esses foram os principais focos da pesquisa.

Tendo como referência a noção de satisfação adotada por Gladstein (1984 apud PUENTE - PALACIOS, 2002) e a adotada por Bastos (1992) sobre o comprometimento, foram diferenciados os níveis do fator satisfação dos participantes da pesquisa com base nos cinco itens da escala validada por PuentePalacios (2002) e os níveis do fator comprometimento com base na escala adaptada por Caixeta e Puente-Palacios (2005). Através das analises dos dados, pode-se afirmar que os membros das equipes estudadas são satisfeitos (escore médio geral de satisfação 4,48) e comprometidos (escore médio geral do comprometimento após a inversão dos dois itens negativos 4,13 ) com as relações interpessoais que trocam com os outros membros da sua equipe. Pois estes valores podem ser assim analisados se forem levadas em conta a margem de variação da escala entre 1 e 5 e os escores 4 ("discordo pouco") e 5 ("concordo totalmente") como indicativos de satisfação e comprometimento propriamente ditos.

Em estudo sobre a avaliação da satisfação e do impacto do trabalho nas equipes de saúde mental, Ishara (2007) descreve que bons relacionamentos no ambiente de trabalho propiciam uma redução das insatisfações no contexto de trabalho. 
Também sobre o tema Souza (2006, p.68) afirma que pesquisadores verificaram que "características pessoais como idade, sexo, nível de escolaridade, tempo no cargo e na empresa, percepção de competência, habilidade, entre outros, são antecedentes diretos do comprometimento organizacional”. A autora conclui que tais resultados indicam a relevância de algumas variáveis individuais na compreensão do fenômeno. Ela também afirma que tendo em vista que essa forma de comprometimento não se desvincula das demais, "é pertinente considerar que essas variáveis, inclusive as auto-avaliativas, também possam estar relacionadas ao comprometimento, quando o foco deste fenômeno for à equipe de trabalho" (SOUZA, 2006, p.69). Diante da defesa citada acima e dos resultados das correlações feitas na presente pesquisa, conclui-se que as características pessoais dos participantes da pesquisa, com relação a sexo e grau de escolaridade, são as variáveis que mais influenciaram no escore médio do comprometimento destes com suas equipes. Ou seja, mesmo sendo as mulheres apenas $27,3 \%$ do total de servidores da penitenciaria, elas são menos comprometidas do que os homens com a equipe e isso fez cair a média do fator (esta característica pessoal também influenciou no nível de satisfação com a equipe).

Já com relação à "variável regime de trabalho" os resultados das correlações apontam que os níveis de satisfação e de comprometimento com a equipe são maiores nas equipes que trabalham em regime de plantão. Isso pode ser explicado pelo fato de que a execução do trabalho neste regime é mais arriscada, pois aqui o contato direto com os internos é mais freqüente e isso consequentemente requer uma maior integração entre os membros das equipes, pois a interdependência na hora de executar as tarefas é maior. Esta explicação tem como base a conclusão apresentada por Puente-Palacios e Borges-Andrade (2005) que no seu estudo sobre o efeito da interdependência da satisfação de equipes de trabalho, os autores relatam que existe relação direta entre interdependência de resultados e satisfação para aqueles que acreditam que suas equipes de trabalho são efetivas.

Um aspecto que deve ser levado em consideração com relação às equipes que trabalham em regime de expediente é a possibilidade destas não terem consolidado o chamado "espírito de equipe". Em parte, isso pode ser exemplificado por meio dos comentários da questão aberta dos questionários por estes servidores. As observações ressaltam que: 
"Por mais satisfeito que eu esteja na equipe, ainda assim acontecem algumas situações, como colegas "escorões", que me deixam chateado."

"Em relação à equipe no geral é complicado a maneira de lidar com as pessoas, pois estas são complicadas na maneira de pensar e agir. Algumas tentam tirar proveito e também não têm respeito pelos outros colegas de trabalho. Já outras, muito pouco, são legais e companheiras."

"As equipes são formadas aleatoriamente, só o tempo para traçar uma equipe padrão."

"Há a necessidade de uma maior interação dos membros da equipe."

Outro aspecto a ser considerado está relacionado à má distribuição das tarefas que acontece entre os servidores das seções administrativas. Esta afirmação também é baseada nos comentários escritos na questão aberta dos questionários. As respostas destacam que:

"O problema da minha equipe é que alguns membros gostam de empurrar o próprio serviço para os outros e acham ruim quando dizemos que no momento não podemos realizar o que eles solicitaram, porque tenho que fazer o meu próprio serviço!"

"Na GEAIT, os técnicos penitenciários são tratados como estagiários, exercendo, além de suas atribuições, as atribuições do pessoal da área de saúde, ficando, dessa forma, sobrecarregados."

Uma Consideração importante a respeito das correlações merece ser apontada: a ausência de correlações significativas entre as variáveis sócio-demográficas (idade, tempo de serviço e cargo) e os fatores Satisfação e Comprometimento. Os resultados apontam que grande parte dos servidores que participaram da pesquisa é nova na penitenciária $(72,7 \%$ dos participantes tinha até um ano de serviço na organização); são Técnicos Penitenciários (72,2\% dos participantes da pesquisa) e que a maioria deles tem entre 26 e 30 anos (43,8\% tinha esta idade). Conclui-se com estes dados que o fato dos Técnicos Penitenciários (que já corresponde 64,6\% do total de servidores da penitenciária) terem menos de um ano de serviço e terem, na sua maioria, entre 26 e 30 anos, não são menos satisfeitos e comprometidos com suas equipes que os demais servidores que já estão há mais tempo na penitenciária. 
No estudo de Puente-Palácios et al. (2005) a conclusão da pesquisa aponta que o tipo de base de poder utilizado pelo supervisor no dia a dia exerce papel importante no desenvolvimento dos focos de comprometimentos afetivos no trabalho, quer sejam com a organização, quer sejam com a equipe. A confirmação desta defesa pode ser observada por meio da resposta da questão aberta que diz:

"Apesar do pouco tempo, gosto muito dessa equipe. Os integrantes colaboram muito para isso. Mas, creio também que o adjunto e o auxiliar colaboram muito para isso, são como líderes e não chefes. Isso faz diferença. Tentam compreender a equipe de trabalho."

Dos questionários que tiveram sua questão aberta preenchida $30 \%$ das observações foram comentários de como os servidores na penitenciária (não só os Técnicos Penitenciários) estão insatisfeitos com o Governo do Distrito federal. Estes servidores não se sentem valorizados e reconhecidos pelo mesmo. Os comentários foram:

"Espero que a categoria Técnico Penitenciário conquiste melhorias salariais bem como outras conquistas necessárias." - Agente Penitenciário.

"O trabalho é bom, a equipe é boa, apenas o salário é ridículo." - Técnico Penitenciário.

"São profissionais sem reconhecimento os técnicos." - Agente Penitenciário.

"Minha equipe me valoriza. Mas o governo não! - Técnico Penitenciário.

"Falta valorização da função de Técnico Penitenciário e falta o governo definir definitivamente o que é melhor para o Sistema Penitenciário, pois atualmente o que se vê é total indiferença." - Agente Penitenciário.

"Na minha equipe a única coisa que falta é salário compatível com nossas atribuições." - Técnico Penitenciário.

Pode-se concluir com essas observações que além das variáveis sóciodemográficas estudadas, fatores externos à equipe são apontados como fonte de Satisfação e Comprometimento com a equipe. 


\section{CONCLUSÃO}

Nessa pesquisa, a Satisfação e o Comprometimento com a equipe foi estudada a partir das reações afetivas dos seus participantes. O principal objetivo foi analisar os níveis de satisfação e comprometimento dos servidores de uma penitenciária do Distrito Federal com suas equipes de trabalho. Já os objetivos específicos do presente estudo eram: descrever as características do ambiente de trabalho das equipes de uma penitenciária, correlacionar os fatores "satisfação e comprometimento" com as variáveis socio-demográficas e comparar o grau de satisfação e de comprometimento das equipes que trabalham em regime de plantão com as que trabalham em regime de expediente.

O estudo do fator satisfação buscou atender às sugestões de agenda de pesquisa de diversos autores, entre eles, Machado (1998), Puente-Palacios (2002) e Souza (2006). Adicionalmente, estudar o comprometimento com a equipe no âmbito da realidade brasileira veio ao encontro ao proposto por Medeiros et al. (2003) e Guimarães e Martins (2008).

O objetivo principal foi alcançado com os resultados obtidos nas análises fatoriais das escalas utilizadas para mensurar os fatores satisfação e comprometimento com a equipe. Os resultados encontrados revelaram satisfação e comprometimento com a equipe por parte da maioria dos participantes da pesquisa. Estes resultados também apontaram que a confiança, os valores, e a lealdade, influenciam nas percepções destes fatores (variáveis presente nos itens do questionário). Dessa forma, conclui-se que os níveis de satisfação e comprometimento com a equipe são afetados pelas relações interpessoais que ocorrem no interior das equipes.

Cabe salientar o fato dos Técnicos Penitenciários (que já corresponde o maior número de servidores da penitenciária) terem menos de um ano de serviço e terem, na sua maioria, entre 26 e 30 anos, não os fazem menos satisfeitos e comprometidos com suas equipes que os demais servidores que já estão há mais tempo na penitenciária.

Também se pode concluir no trabalho, através das observações feitas na questão aberta dos questionários, que além das variáveis sócio-demográficas estudadas, fatores externos à equipe (como salário e reconhecimento do serviço) 
não só influenciam nos níveis de Satisfação e Comprometimentos com a equipe como também com a organização.

Uma vez apresentadas as principais conclusões do presente trabalho, cabe destacar as principais contribuições do estudo. Primeiramente, ressalta-se que este trabalho foi precursor ao descrever as relações sociais que ocorrem entre os servidores de uma penitenciária e suas conseqüências em relação à satisfação e o comprometimento com a equipe, pois na literatura científica nacional não foram identificados autores que abordassem, neste tipo de organização, o trabalho destes seus servidores da forma que foi proposta aqui. Espera-se que os resultados encontrados contribuam e influenciem no desenvolvimento de novas pesquisas sobre quais variáveis influenciam nas relações de trabalho e, consequentemente, aumentam o desempenho das equipes.

Em segundo lugar essa pesquisa aponta como estão sendo desenvolvidas as relações de trabalho dos novos servidores da penitenciária (Técnicos Penitenciários) com os antigos servidores (demais cargos) existentes no sistema. Os resultados de satisfação e comprometimento levam à conclusão que de forma geral são boas as relações interpessoais entre os novos servidores e os antigos, apesar de algumas reclamações. E em terceiro lugar este pesquisa traz também outras implicações práticas para os chefes, supervisores e profissionais que administram as equipes, uma vez que os resultados apontam que as mulheres e os servidores do expediente são os menos satisfeitos e comprometidos, é possível criar programas de integração e desenvolvimento do chamado "espírito de equipe" destes servidores.

Ainda que apresentadas algumas contribuições, as limitações do presente trabalho e sugestões de estudos futuros também devem ser apresentadas.

Em primeiro lugar, é fundamental considerar a especificidade da amostra estudada. $\mathrm{Na}$ investigação da pesquisa, os participantes eram todos membros de equipes que trabalham na mesma penitenciária. Portanto, deve-se tomar cuidado ao generalizar os resultados desse trabalho para as demais penitenciárias do sistema do Distrito Federal. Pois as equipes aqui estudadas apresentavam características que podem não ser comuns a outras equipes, pois as demais penitenciárias, exceto uma, têm estruturas físicas diferentes da estudada. Outro limite da pesquisa advém da participação da autora em uma das equipes pesquisadas, o que poderia ter introduzido algum viés de interpretação. 
Contudo, a partir dessas limitações e da análise dos resultados atingidos propõese uma agenda para a realização de novas pesquisas que permitam confirmar ou refutar os resultados aqui obtidos junto a servidores de outras penitenciárias e pesquisas que investiguem outras variáveis internas e externas à equipe que podem influenciar no desempenho e nas inter-relações pessoais entre os membros das equipes. 


\section{REFERÊNCIAS}

BASTOS, A. V. B. Medidas de Comprometimento no contexto de trabalho: um estudo preliminar de validade discriminante. Revista semestral do instituto de Psicologia da Pontifícia Universidade do Rio Grande do Sul, Porto Alegre, v. 23, n. 2, p.29-48, jul/dez. 1992.

BASTOS, A. V. B. Comprometimento no trabalho: a estrutura dos vínculos do trabalhador com a organização, a carreira e o sindicato. 1994. 216f. Tese de (Doutorado em Psicologia) - Instituto de Psicologia, Universidade de Brasília, Brasília, 1994.

BERSOU, M. L. T.; BERSOU, L. Considerações sobre a evolução competitiva de empresas do ponto de vista de formação de equipes. Revista de Administração de Empresa, São Paulo, v. 37, n. 4, p. 6-10, out/dez. 1997. Disponível em: < http://www.rae.com.br/artigos/268.pdf>. Acesso em: 20 set. 2009.

BORBA, A. C. P. Potência em equipes: desenvolvimento de uma medida. 2007. 94f. Dissertação (Mestrado em Psicologia Social, do Trabalho e das Organizações).

- Programa de Psicologia Social, Universidade de Brasília, Brasília, 2007.

CAIXETA, P.; PUENTE-PALACIOS, K.. Adaptação de uma escala de avaliação do comprometimento com a equipe de trabalho. Resumos do PIBIC -2005. Brasília. 2005.

CARDOSO. A. S. F. Análise do processo grupal de uma equipe de enfermagem. 2009. 102f. Dissertação (Mestrado em enfermagem) - Programa de Pós-Graduação em Enfermagem , Universidade Federal do Rio Grande do Sul, Porto Alegre,2009.

CARTWRIGHT, D. Como mudar as pessoas: algumas aplicações da teoria de dinâmica de grupo. Revista de Administração Contemporânea, São Paulo, vol.6, n.20, p. 129-147, out/dez. 1966. Disponível em: <http://www.rae.com.br/artigos/2524.pdf>. Acesso em: 16 set. 2009.

CRESWELL, J.W. Revisão de literatura. In: Projeto de pesquisa: métodos qualitativos, quantitativos e misto. 2. ed. Porto Alegre: Artmed, 2007. cap. 2.

DEPARTAMENTO PENITENCIÁRIO NACIONAL. Sistema Penitenciário no Brasil diagnósticos e propostas. Brasília, 2007. Disponível em: $<$ http://www.mi.gov.br/depen/data/Pages/MJD574E9CEITEMIDC37B2AE94C684006 8B1624D28407509CPTBRIE.htm >. Acesso em: 26 set. 2009. 
Diário Oficial do Distrito Federal. Brasília, № 225, p. 9, 26 de Nov. de 2007. Arquivo disponível

em: $<$ http://www.buriti.df.gov.br/ftp/diariooficial/2007/11Novembro/DODF\%20225\%202611-2007/Seção01-\%20225.pdf>. Acesso em: 20 set. 2009.

DUHÁ, A. H. Organização de equipes efetivas: Variáveis, processos e estratégia de investigação. 2007. 96f. Tese (Doutorado em Psicologia) - Faculdade de Psicologia, Pontifícia Universidade Católica do Rio Grande do Sul, Porto Alegre, 2007.

FERNANDES, R. C. P. et al. Trabalho e cárcere: um estudo com agentes penitenciários da Região Metropolitana de Salvador, Brasil. Cad. Saúde Pública, Rio de Janeiro, 18(3):807-816, maio/jun. 2002. Disponível em: $<$ http://www.scielosp.org/pdf/csp/v18n3/9308.pdf>>. Acesso em: 20 set. 2009.

FREITAS, A. A. Aplicação dos estilos de aprendizagem na formação de equipes: um estudo de caso. 2007. 132f. Dissertação (Mestrado em Engenharia de Produção) - Departamento de Engenharia de Produção, Universidade de São Paulo, São Carlos, 2007

GUIMARÃES; V. F.; MARTINS, M. C. F. Bases de poder do supervisor, conflitos intragrupais e comprometimento organizacional e com a equipe. Revista

Psicologia: Organizações e Trabalho, vol.8, n.2, p.54-78. jul/dez. 2008. Disponível em: < http://www.periodicos.ufsc.br/index.php/rpot/article/view/10159/9395> . Acesso em: 15 set. 2009.

ISHARA, S. Equipes de saúde mental: avaliação da satisfação e do impacto do trabalho em hospitalização integral e parcial. 2007. 153f. Tese (Doutorado em Saúde Mental) - Faculdade de Medicina, Universidade de São Paulo, Ribeirão Preto, 2007

MACHADO, M. S. Equipes de trabalho: sua efetividade e seus preditores. 1998. 157f. Dissertação (Mestrado em Psicologia Social, do Trabalho e das Organizações) - Instituto de Psicologia, Universidade de Brasília, Brasília, 1998.

MAXIMIANO, A.C. A. Introdução à administração. 5 ed. São Paulo: Atlas. 2000.

MEDEIROS, C. A. F. et al.Comprometimento Organizacional: o Estado da Arte da Pesquisa no Brasil. Revista de Administração Contemporânea,v. 7, n. 4, p. 187-209, out/dez. $2003 . \quad$ Disponível em: $<$ http://www.scielo.br/pdf/rac/v9n3/v9n3a04.pdf>. Acesso em: 15 set. 2009. 
NASCIMENTO, A. M. F.R. et al. Tendências atuais das políticas de recursos humanos: um estudo de caso numa empresa têxtil da Paraíba. VI SEMEAD Seminários em Administração, São Paulo, março de 2003. Disponível em: < http://www.ead.fea.usp.br/Semead/6semead/RH/022RH>. Acesso em: 15 set. 2009.

PEDUZZI, M. Equipe multiprofissional de saúde: conceito e tipologia. Rev Saúde Pública, São Paulo, vol.35, no.1, p. 103-109, 2001. Disponível em: http://www.scielosp.org/scielo.php?script=sci arttext\&pid=S003489102001000100016>. Acesso em: 20 set. 2009.

PIERUCCINI, J. C. O desenvolvimento de equipes na melhoria de resultados organizacionais. 2002. 117f. Dissertação (Mestrado em administração) - Programa de Pós-Graduação em Administração, Universidade Federal do Rio Grande do Sul, Caxias do Sul, 2002.

PUENTE-PALACIOS, K. Depender ou não depender, eis a questão: um estudo multinível do efeito de padrões de interdependência na satisfação dos membros das equipes de trabalho. 2002. 217f. Tese (Doutorado em Psicologia) Instituto de Psicologia, Universidade de Brasília, Brasília, 2002.

PUENTE-PALÁCIOS, K. et al. Validação de uma escala de comprometimento afetivo com a equipe. In: In: Sociedade Interamericana de Psicologia (Org). Resumos de comunicação científica, 30 ㅇ Congresso Interamericano de Psicologia. Buenos-Aires, Argentina. 2005.

PUENTE-PALACIOS, K.; BORGES-ANDRADE, J. E. O efeito da interdependência na satisfação de equipes de trabalho: um estudo multinivel. Revista de Administração Contemporânea,v. 9, n. 3, p. 57-78, jul/dez. 2005. Disponível em: <http://www.scielo.br/pdf/rac/v9n3/v9n3a04.pdf>. Acesso em: 15 set. 2009.

PUENTE-PALACIOS, K.; CARNEIRO, B. P. Adaptação de uma escala de avaliação do clima social ao contexto de equipes de trabalho. Revista Psicologia:

Organizações e Trabalho, vol.5, n.1, p.45-70. jan/jun. 2005. Disponível em: < http://www.periodicos.ufsc.br/index.php/rpot/article/view/7773>. Acesso em: 15 set. 2009.

PUENTE-PALACIOS; K. E.; SEIDL, J.; SILVA, R. A. D. Ser ou parecer diferente: o papel da diversidade na satisfação de equipes de trabalho. Revista Psicologia: Organizações e Trabalho, vol.8, n.2, p.79-97. jul/dez. 2008 Disponível em: $<$ http://www.periodicos.ufsc.br/index.php/rpot/article/view/10160/9396>. Acesso em: 15 set. 2009.

SACOMANO NETO, M.; ESCRIVÃO FILHO, E. Estrutura organizacional e equipes de trabalho: estudo da mudança organizacional em quatro grandes empresas 
industriais. Gestão \& Produção, v.7, n.2, p. 136-145, ago. 2000. Disponível em: $<$ http://www.scielo.br/pdf/gp/v7n2/a04v7n2.pdf >. Acesso em: 20 set. 2009.

SALLA, F. As rebeliões nas prisões: novos significados a partir da experiência brasileira. Sociologias, Porto Alegre, ano 8, no 16, p. 274-307, jul/dez 2006. Disponível em: <http://www.scielo.br/pdf/soc/n16/a11n16.pdf>. Acesso em: 15 set. 2009.

SIQUEIRA, M. M. M.; GOMIDE JR., S. Vínculos do indivíduo com o trabalho e com a organização. In: ZANELLI, J. C.; BORGES-ANDRADE, J. E.;BASTOS, A. V. B. (Org.). Psicologia, Organizações e Trabalho no Brasil. Porto Alegre: Artmed, 2004. p. 300-328.

SOUSA, V. D.; DRIESSNACK, M.; MENDES, I. A. C. Revisão dos desenhos de pesquisa relevantes para enfermagem. Parte 1: desenhos de pesquisa quantitativa. Rev Latino-am Enfermagem, Ribeirão Preto, vol.15, n.3, p. 502-507, maio/jun. 2007. Disponível em: <http://www.scielo.br/pdf/rlae/v15n3/pt v15n3a22.pdf>. Acesso em: 20 set. 2009.

SOUZA, M. G. S. O papel do autoconceito profissional na efetividade das equipes de trabalho. 2006. 145f. Dissertação (Mestrado em Psicologia) - Instituto de Psicologia, Universidade de Brasília, Brasília, 2006. 


\section{Anexo A - Organograma}

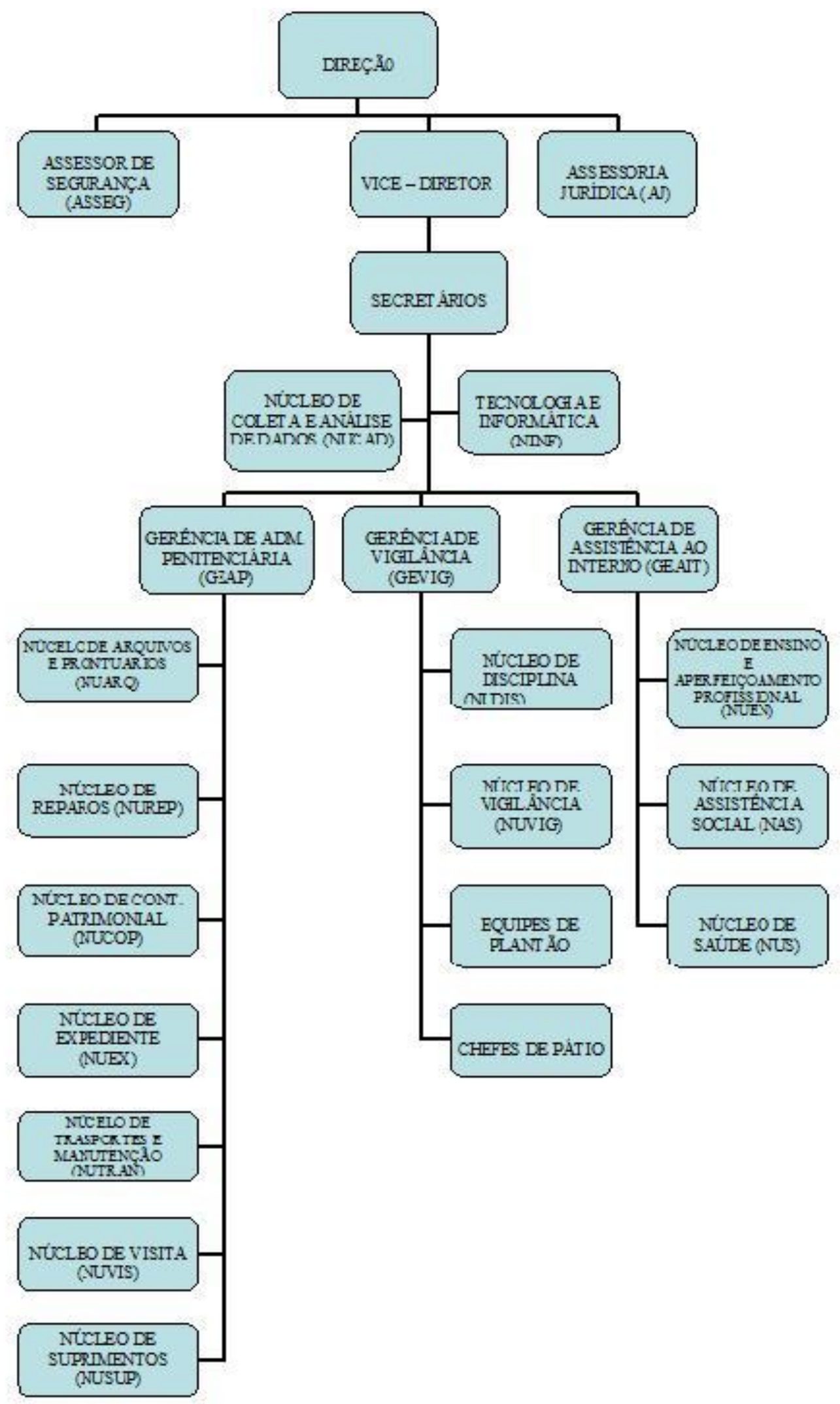




\title{
7.2. Anexo B - Questionário
}

\author{
4 \\ Universidade de Brasília - UnB \\ Faculdade de Economia, Administração, \\ Contabilidade e Ciência da Informação e \\ Documentação (FACE) \\ Departamento de Administração
}

Prezado(a) Senhor(a),

A presente pesquisa faz parte da minha monografia de conclusão do curso de Administração na Universidade de Brasília. O objetivo principal deste questionário é analisar os níveis de satisfação e comprometimento dos servidores desta penitenciária com sua equipe de trabalho.

Para tanto, gostaria que o(a) Sr.(a) respondesse todas as questões sendo o mais sincero possível, pois não há respostas certas ou erradas.

O questionário possui duas partes distintas. A primeira avalia aspectos da satisfação e do comprometimento com a equipe. Já a segunda parte destina-se a coletar informações sobre os participantes da pesquisa a fim de caracterizá-los.

Saliento que as informações aqui prestadas serão analisadas de forma agregada e sem a identificação dos participantes garantindo assim o sigilo e 0 anonimato dos mesmos.

Por favor, responda a TODOS os itens.

Obrigada por dedicar parte do seu tempo para responder a todas estas questões e, é claro, todos os seus comentários são bem-vindos.

Estarei à disposição para quaisquer esclarecimentos. Caso o(a) Sr.(a) deseje conhecer os resultados dessa pesquisa, envie um e-mail solicitando. 
ESCALA DE SATISFAÇÃO COM A EQUIPE DE TRABALHO: escala validada por Puente-Palacios (2002)

Responda cada item utilizando um dos códigos seguintes:

\begin{tabular}{|c|c|c|c|c|}
\hline 1 & 2 & 3 & 4 & 5 \\
$\begin{array}{c}\text { Discordo } \\
\text { Totalmente }\end{array}$ & $\begin{array}{c}\text { Discordo } \\
\text { Pouco }\end{array}$ & Em dúvida & $\begin{array}{c}\text { Concordo } \\
\text { Pouco }\end{array}$ & $\begin{array}{c}\text { Concordo } \\
\text { Totalmente }\end{array}$ \\
\hline
\end{tabular}

No espaço ao lado de cada afirmativa sobre seu ambiente de trabalho nesta empresa, marque com um $\mathrm{X}$ o número que melhor corresponda à sua percepção, conforme os critérios acima definidos. Escolha apenas uma resposta para cada item e, por gentileza, responda a todos os itens.

1. Em relação aos membros da minha equipe de trabalho, eu sinto confiança de que manteremos boas relações no futuro.

1( ) 2( ) 3( ) 4( ) 5( )

2. Tenho sentimentos positivos sobre a forma como trabalhamos juntos na minha equipe.

1( ) 2( ) 3( ) 4( ) 5( )

3. Estou satisfeito com a forma em que trabalhamos juntos na minha equipe. 1( ) 2( ) 3( ) 4( ) 5( )

4. Sinto-me bem a respeito do relacionamento que mantenho com os membros da minha equipe de trabalho.

$1($ ) 2( ) 3( ) 4( ) 5( )

5. Confio completamente nos membros da minha equipe.

$1($ ) 2( ) 3( ) 4( ) 5( ) 
ESCALA DE COMPROMETIMENTO COM A EQUIPE: escala validada por Caixeta e Puente-Palacios (2005)

Responda cada item utilizando um dos códigos seguintes:

\begin{tabular}{|c|c|c|c|c|}
\hline 1 & 2 & 3 & 4 & 5 \\
$\begin{array}{c}\text { Discordo } \\
\text { Totalmente }\end{array}$ & $\begin{array}{c}\text { Discordo } \\
\text { Pouco }\end{array}$ & Em dúvida & $\begin{array}{c}\text { Concordo } \\
\text { Pouco }\end{array}$ & $\begin{array}{c}\text { Concordo } \\
\text { Totalmente }\end{array}$ \\
\hline
\end{tabular}

No espaço ao lado de cada afirmativa sobre seu ambiente de trabalho nesta empresa, marque com um $\mathrm{X}$ o número que melhor corresponda à sua percepção, conforme os critérios acima definidos. Escolha apenas uma resposta para cada item e, por gentileza, responda a todos os itens.

1. Conversando com amigos, eu sempre me refiro a minha equipe de trabalho como uma grande unidade para a qual é ótimo trabalhar.

1( ) 2( ) 3( ) 4( ) 5( )

2. Eu julgo que os meus valores são muito similares aos valores defendidos pela equipe de trabalho a qual pertenço.

$1($ ) 2( ) 3( ) 4( ) 5( )

3. Eu me sinto orgulhoso dizendo às pessoas que sou parte da minha equipe de trabalho.

1( ) 2( ) 3( ) 4( ) 5( )

4. A minha equipe de trabalho realmente inspira o melhor em mim, para o progresso no desempenho das minhas atividades.

1( ) 2( ) 3( ) 4( ) 5( )

5. Eu me sinto contente por ser parte desta equipe, comparando com as outras que conheço.

1( ) 2( ) 3( ) 4( ) 5( )

6. Eu realmente me interesso pelo destino da equipe a qual pertenço.

$1($ ) $2($ ) 3( ) 4( ) 5( )

7. A minha equipe é a melhor de todas para se trabalhar.

1( ) 2( ) 3( ) 4( ) 5( )

8. Decidir trabalhar nesta equipe foi um erro de minha parte.

1( ) 2( ) 3( ) 4( ) 5( )

9 Eu sinto pouco lealdade da equipe em que trabalho. 


\section{SEGUNDA PARTE}

Para finalizar, solicito-Ihe a gentileza de responder aos seguintes itens:

1 - Sexo:

1.( ) Masculino 2.( ) Feminino

2 - Regime de trabalho:

1.( ) Expediente (Pule a questão quatro)

2.( ) Plantão (Pule a questão três)

3 - Expediente na seção:
1.( ) ASSEG
4.( ) NUSUP
2.( ) GEAIT
5.( ) NUTRAM
7.( ) NUARQ
3. ( ) GEVIG
6. ( ) NUVIG
8.( ) AJ
9.( ) Outro:

4 - Plantão na equipe:
1.( ) Alfa
2.( ) Bravo
3.( ) Charlie
4. ( ) Delta

5 - Idade:
1.( ) 18 a 25 anos
4.( ) 36 a 40 anos
7.( ) acima de 50 anos
2.( ) 26 a 30 anos
5. () 41 a 45 anos
3.( ) 31 a 35 anos
6. ( ) 46 a 50 anos

6 - Tempo de serviço nessa empresa:
1.( ) Até 1 ano
4.( ) acima de 10 até 15 anos
2.( ) acima de 1 até 5 anos
5.( ) acima de 15 até 20 anos
3.( ) acima de 5 até 10 anos
6. () acima de 20 anos

\section{7 - Seu cargo:}
1.( ) Técnico Penitenciário
4. ( ) Terceirizado
2. ( ) Policial Militar
5. ( ) Outros:
3. ( ) Agente Penitenciário

8 - Grau de escolaridade:
1. ( ) Ensino médio
4. ( ) Mestrado
2.( ) Superior incompleto
5.( ) Doutorado
3. ( ) Superior

Utilize esse espaço para fazer alguma observação, se desejar: 